\title{
Financing Constraints, Product Market Competition, and Business Cycle Sensitivity
}

\author{
Peter Pontuch*
}

This version: November 25, 2011

\begin{abstract}
We analyze the interactions between financing constraints and product market competition. Financially constrained firms face restricted access to external finance during economic downturns, precisely when their internal funds decrease. This leads to vicious circle dynamics. We argue that in competitive industries cash flows are particularly sensitive to aggregate shocks, and the adverse dynamics are amplified. We find significant support for this hypothesis in firms' operating profitability and fixed investment. The adverse effects of financing constraints are increasing in the level of product market competition. Market valuations do not take into account these differences in fundamental risk. Unconstrained firms in competitive industries earn positive abnormal returns (on average 24-40 bp per month), especially following periods of macroeconomic distress. Furthermore, financing constraints affect competitive mechanisms within industries. The industry-average level of financing constraints tends to reduce the intra-industry mean-reversion of firm profitability. Again, this regularity is not priced: highly profitable firms earn alphas of 20-29 bp per month if they operate in industries with many constrained firms, but virtually no alphas if their industries have few constrained firms.
\end{abstract}

Keywords: financing constraints, product market competition, industry concentration, business cycle, profitability, investment.

JEL Classifications: G32, L11.

\footnotetext{
*Université Paris-Dauphine - DRM Finance - Place du Maréchal de Lattre de Tassigny - 75775 Paris Cedex 16 - pontuch@gmail.com. I am deeply grateful to Gilles Chemla (my advisor) and Gordon Phillips. I also thank Murillo Campello (discussant at FMA European Conference 2011), Sandeep Dahiya, Michael Faulkender, Denis Gromb, Gerard Hoberg, Jayant Kale, Gaëlle Le Fol, Vojislav Maksimovic, and Luboš Pástor for valuable suggestions. I also thank seminar participants at Université Paris-Dauphine, the Universty of Maryland, College Park, Georgetown University, ESCP Europe, and INSEAD Doctoral workshop for their comments and ideas. All errors are my own. I gratefully acknowledge financial support from the FBF Chair in Corporate Finance, as well as kind hospitality of the Department of Finance at the University of Maryland, College Park.
} 


\section{Introduction}

It is widely acknowledged that corporate earnings are procyclical and more volatile than the overall economy due to their junior status relative to other claims. However, there is a high degree of heterogeneity in earnings procyclicality at the firm level. Some of this procyclicality is driven by industry demand (Gomes, Kogan, and Yogo (2009)). But relatively little is known about other firm- and industry-level determinants of this heterogeneity, despite the obvious relevance of this question.

In this paper we focus on two such determinants, namely financing constraints and product market competition. We show that the effects of these two factors are interrelated. The intuition behind this idea is simple. The literature on financing constraints suggests that (i) constrained firms' investment is more dependent on internal funds (see Fazzari, Hubbard, and Petersen (1986) and subsequent studies), and (ii) constrained firms are more subject to a flight to quality in capital markets at the onset of an economic downturn (Bernanke, Gertler, and Gilchrist (1996)). A vicious circle dynamics is at play: constrained firms face restricted access to external finance exactly when internal funds tend to fall. This fall implies insufficient financing for current operations and investment projects, which further reduces available internal funds etc.

In this paper we argue that the severity of these adverse dynamics depends on the initial shock to cash flows. We propose to study the level of competition in the product market as a factor affecting the initial shock to internal funds. Concentrated industries tend to be more insulated from aggregate shocks (Rotemberg and Saloner (1986), Hou and Robinson(2006)). The initial adverse shock to internal funds due to worsening macro conditions will likely be stronger for firms in competitive industries. The vicious circle dynamics in financially constrained firms should therefore be strongest in highly competitive industries.

It has been recently documented that financing constraints have significant real effects on firms' policies during adverse economic conditions. Campello, Graham, and Harvey (2010) perform a CFO survey during the most recent financial turmoil and show that credit constrained firms reduced their capital expenditure, $\mathrm{R} \& \mathrm{D}$, marketing expenditures, and employment sig- 
nificantly more than unconstrained firms. One of our objectives is to see whether financing constraints have more real effects on firms in highly competitive industries compared to concentrated industries.

We first show that financing constraints increase the macro-sensitivity of firms' operating performance. Compared to highly constrained firms, unconstrained firms are about $30 \%$ less sensitive to GDP and about 50 to $75 \%$ less sensitive to changes in the bond spread. Consistent with our hypothesis we find that these adverse effects of financing constraints are significantly amplified by product market competition. Stated differently, the difference of business cycle sensitivity between constrained and unconstrained firms is increasing in the level of competition.

We also examine the real effects of financing constraints. We find that the sensitivity of fixed investment to aggregate economic conditions is increasing in financing constraints. Industry competition further amplifies this sensitivity in the highly constrained subsample, whereas no such significant effect is present in the low constraints subsample. These results are consistent with the idea that industry competition also amplifies the real effects of financing constraints.

We also analyze investments in net working capital and inventories: the effect of competition has the same sign but is not significant. Lastly, employment growth's sensitivity to aggregate shocks is somewhat increasing in financing constraints, but the effect of industry concentration seems to be completely absent.

Our asset pricing tests reveal that market valuations do not completely incorporate the above differences in fundamental risk. We find that portfolios of unconstrained companies in competitive industries earn abnormal positive returns. A moving window analysis reveals that this abnormal return is mostly earned following periods of economic turmoil. On the other hand, constrained firms earn negative returns in these periods and virtually no abnormal returns in normal periods.

Finally, we study how financing constraints affect competitive mechanisms in industries. We present a set of results about cross-sectional mean-reversion of firm profitability. At the industry level, the overall percentage of constrained firms significantly reduces the speed of 
mean reversion of firm profitability. Increasing the percentage of constrained firms in an industry by 50 percentage points reduces the mean reversion speed by about 12 percentage points. This suggests that financially constrained competitors are less aggressive. Abnormal levels of profitability can be sustained for a longer period in industries with a high percentage of constrained rivals. Again, this regularity is not fully priced: higly profitable firms earn significant alphas of 20-29 bp per month if they operate in industries with many constrained firms, but virtually no alphas if their industries have few constrained firms.

Our paper contributes to the existing literature on the real effects of financing constraints. We show that product market competition is an important determinant of the severity of the real effects of financing constraints. Companies' operating performance and investment behavior are more affected by financial constraints if the firm operates in a highly competitive industry.

Our results have implications for financial analysis at both the firm level (e.g. for valuation and risk assessment) and the aggregate level (e.g. financial accelerator effects). Our study also has implications for policy design. It points to the fact that firms deemed as financially constrained and operating in highly competitive industries are the most fragile element of the corporate universe in an economic downturn, especially if it is accompanied by a worsening of overall credit conditions. Policies aimed at improving access to financing for SMEs during a credit crunch should focus particularly on highly competitive industries.

The article is organized as follows. In section 2 we present related literature and formulate our research hypotheses. We then present our data and discuss measures of financing constraints and industry concentration in section 3. Our results on the sensitivity of profitability levels are presented in section 4 . We analyze the real effects of financing constraints in section 5. Asset pricing tests are performed in section 6 . Section 7 presents our findings on the effect of financing constraints on industry competitive mechanisms. 


\section{Background and research questions}

The complex relationships between macroeconomic fluctuations, markups and market structure were studied by Hall (1986), who suggests that a large number of U.S. industries operate above competitive markup levels. This fact has implications for the macroeconomics of productivity shocks: noncompetitive structures could be a source of underutilization of resources and aggregate fluctuations. Other contributions in this field include Domowitz, Hubbard, and Petersen (1986), Bils (1987), Rotemberg and Saloner (1986), Rotemberg and Woodford (1991), and Haskel, Martin and Small (1995). Oliveira Martins and Scarpetta (2002) give a brief survey of the related theoretical and empirical literature. They note that there is no consensus on whether markups are procyclical or countercyclical, the latter requiring generally some non-competitive elements in the model (e.g. monopolistic competition with pro-cyclical product variety, or oligopoly with collusions). For instance, Rotemberg and Saloner (1986) develop a model of countercyclical markups in an oligopolistic market with implicit collusions. The basic idea of the model is that the collusion agreement is much less stable under economic expansions (where demand is high and punishments hurt less), than in economic downturns.

Elements of financing frictions were formalized in the context of markups by Chevalier and Scharfstein (1996) who develop and test a model of countercyclical markups with capital market imperfections where consumers face a switching cost. Financially constrained firms finance their operations in downturns by increasing relative prices and preserving short-term profits, while sacrificing long-term market shares and profits. Hence their markups are countercyclical, making their profits smoother.

How should one reconcile this result with a more traditional and intuitive view summarized in Bernanke, Gertler and Gilchrist (1996), namely that constrained firms tend to suffer in recessions earlier and more than unconstrained firms? In fact, we need to point out that Chevalier and Scharfstein present a setting with a limited number of firms and with consumers facing switching costs. These costs generate market power for firms which they can use to survive low demand states by temporarily charging relatively higher prices, at the expense of their long-term market share. The setting is therefore closer to an oligopoly, which further 
motivates our study of the interaction between financing constraints and product markets.

A seminal work by Fazzari, Hubbard and Petersen (1988, FHP) introduced the cash flow sensitivity of investment as indicator of financing constraints. Hubbard (1998) summarizes the main reasons why investment may respond more to changes in net worth of constrained firms and surveys subsequent work on the subject. A rich body of literature was generated following the critique by Kaplan and Zingales (1997, KZ) who object to the idea that cash flow sensitivity of investment should be increasing in the level of constraints.

In one of the later extensions into asset pricing Lamont, Polk and Saá-Requejo (2001) study a common factor in stock returns related to financial constraints (measured by the KZ index), but two unexpected results show up: this factor earns on average a negative risk premium and the constraints factor does not seem to respond to macroeconomic variables. Moyen(2004) tries to reconcile FHP and KZ and proposes a model of investment/cash flow sensitivity where two special cases are consistent with either FHP or KZ. Whited and Wu (2006) propose an alternative index to the KZ index, using a structural model of investment. They find evidence of a common financial constraints factor in stock returns, which earns a positive but statistically not significant premium. Interestingly, controlling for financing constraints eliminates the size premium.

More recently, Gomes, Yaron and Zhang (2006) propose an investment asset pricing model where financing constraints appear as a common factor in the cross-section of stock returs and where the negative consequences of financing constraints are pro-cyclical. Livdan, Sapriza and Zhang (2009) incorporate dynamic debt into a production asset pricing model and provide evidence in simulated data of a priced financing constraints factor, giving a slight superiority to the WW index over the KZ index.

Product market competition was recently studied in finance in the context of the cross section of stock market returns by Hou and Robinson (2006), who show that firms in concentrated industries earn lower returns even after controlling for standard risk factors. They attribute this result to either a conservative innovation policy, or to barriers against rival entry and insulation from aggregate shocks. Gaspar and Massa (2006) find that industry competition 
increases idiosyncratic risk of firms. The focus on firms' resistance to individual cost shocks, as opposed to systematic aggregate shocks studied in our paper. Hoberg and Phillips (2010) analyze industry dynamics related to valuation booms in competitive and noncompetitive industries. They show that competitive pressure following a boom in competitive industries tends to reduce future profitability, leading to a sharp drop in sector valuation.

The interaction between product market competition and financing constraints has received much less attention in the literature. Kovenock and Phillips (1997) argue that leverage-induced constraints encourage passive product market behavior while the rivals become more aggressive. Campello (2003) confirms at the industry level the prediction by Chevalier and Scharfstein (1996) of countercyclial markups generated by leverage-induced constraints. Campello (2003) also shows at the firm level that during economic downturns financial constraints penalize the market share growth of firms operating in industries with low leverage levels, while it has little effect in industries with high leverage. Povel and Raith (2004) study the case of a duopoly with one firm financially constrained and show that the constrained firm tends to have a lower market share due to cost disadvantages, while both firms benefit from a higher price than under full competition. We should note that their definition of constraints is closer to the notion of financial dependence on external funding.

We build on two main ideas explored in the literature on financing constraints. The first one is that internal cash flows significantly affect constrained firms' investment activity (Fazzari, Hubbard, and Petersen (1986)). According to the second view-developed in macroeconomics as the financial accelerator-firms facing high agency costs (i.e. financially constrained firms) are subject to a flight to quality in the capital markets in the early stages of economic slumps, implying an earlier and stronger reduction of their economic activity (see Bernanke, Gertler, and Gilchrist (1996)). The two views taken altogether implicitly point to a vicious circle dynamics. Financially constrained firms have more difficulties with raising external finance exactly when internal cash flows are lowest. These low internal funds provide for insufficient financing of current operations and investments, which implies further reduction in activity and in internal funds etc. 
We argue that the amplitude of this adverse effect strongly depends on the initial shock to internal cash flows. We propose to introduce a factor that affects the initial shock to internal funds: the level of competition in the product market. Hou and Robinson (2006) consider industry concentration as a partial insulation from macro shocks due to higher barriers of entry. There are at least two other reasons why concentrated industries should be less exposed to adverse shocks. First, if collusion mechanisms work better in downturns (as in Rotemberg and Saloner (1986)), then concentrated industries will enjoy higher markups in downturns that will partially compensate for the falling demand. Second, if consumers face high switching costs, firms in concentrated markets will be able to steal some of the consumer surplus to support their own cash flows in the short run (as in Chevalier and Scharfstein (1996), and Campello and Fluck (2006)).

Given that the initial fall in internal funds will be stronger in competitive industries (an assumption strongly supported in our data), the subsequent adverse dynamics following a flight to quality in credit markets should be more severe for constrained firms in highly competitive industries. We therefore address the following research questions: (i) What are the effects of financing constraints on the operating performance and the investment behavior of firms?, and (ii) Are these real effects affected by industry concentration? Lastly, we will explore a reverse relationship between the two factors: (iii) Do financing constraints affect the competitive mechanisms in industries?

Based on the related literature and economic reasoning, we formulate the following hypotheses:

\section{H1: Firms in concentrated industries are better insulated from aggregate shocks.} Firms enjoying market power in concentrated industries can pass some of the effects of adverse aggregate shocks on to their customers. Hence, profitability of firms in concentrated industries is less exposed to the business cycle, while the profitability of firms in competitive industries is more sensitive to the overall economy. A rationale for this hypothesis is either barriers to entry of potential rivals as in Hou and Robinson (2006), better functioning of collusion mechanisms in recessions as in Rotemberg and Saloner (1986), or consumer switching costs (Chevalier and 
Scharfstein (1996), Campello and Fluck (2006)).

H2: Firms subject to financing constraints are more affected by aggregate shocks than unconstrained firms. Constrained firms are subject to a flight to quality in capital markets at early stages of economic downturns as in Bernanke, Gertler, and Gilchrist (1996). Given that internal cash flows are depressed during recessions, they have to reduce their activity more than unconstrained firms due to a vicious circle mechanism.

H3: The effects of financing constraints in downturns are higher in competitive industries than in concentrated industries. Per H1, firms operating in competitive industries have their internal cash flows more sensitive to adverse aggregate shocks. If a constrained firm operating in a competitive industry is subject to a flight to quality, as per H2, it can finance a lower part of its operations and investment internally than if it were operating in a concentrated industry. Overall it reduces its activity more than a firm in a concentrated industry.

H4: Financing constraints significantly affect the mean-reversion of firm profitability. We expect that a firm can sustain abnormal levels of profitability for a longer time if a large proportion of its rivals are financially constrained. We use a similar logic as Chevalier and Scharfstein (1996).

We will address H1-H3 by first studying the business cycle sensitivity of operating profitability of firms. As a second step we will analyze real effects in terms of fixed investment, net working capital and in particular inventories, and employment. We address $\mathrm{H} 4$ in the last section where we will estimate a simple model of profitability mean-reversion. 


\section{Data description}

\subsection{Sample firms}

We use all data on U.S. public companies over the period 1977 to 2009 from the CRSP Compustat merged database (CCM). We drop financial companies (SIC between 6000 and 6999) and utilities (SIC between 4900 and 4999) due to a specific status of these two industries. We drop firm-years with total assets below $\$ 10$ million or with common equity below $\$ 5$ million, as in Fama and French (2000). We require valid (and non-negative, where applicable) data on total assets, total liabilities, property, plant\&equipment, shares outstanding, share price, sales, net income, income before extraordinary items, costs of goods sold, common and preferred dividends.

We define operating profitability (ROA) as earnings before extraordinary items and interest divided by total assets. Book equity is total assets less total liabilities less preferred stock plus balance sheet deferred taxes and tax credits (our definitions follow Fama and French, 2000). Market to book ratio is the market value of equity (shares outstanding times end-of-year share price) plus total book assets less book equity divided by total book assets.

We winsorize all ratio variables at the $1 \%$ level. We have in total 78,537 firm-years. Our average cross-section is 2,380 observations, the smallest one being 1,350 observations in 1977, the largest one 3,362 in 1998. We present the number of observations in each year in table 1.

We present summary statistics of our sample in table 2 . The median asset profitability is $6.7 \%$, while the median ROE is somewhat higher at $8.4 \%$. The median M/B of assets is 1.28 , while the median real sales growth is about $4.8 \%$ for the median firm. Median total payout is only $11.7 \%$. Median investment rate is at $4.7 \%$ of assets.

\subsection{Business cycle variables}

We use the following raw macroeconomic data from the Federal Reserve data base ${ }^{1}$ : real annual GDP, the 3-month Treasury bill rate, 10-year Treasury note rate, 3-month non-financial

\footnotetext{
${ }^{1}$ We used the data download facility on the Fed's web site www.federalreserve.gov/releases.
} 
Commercial paper rate ${ }^{2}$, and yields on seasoned Aaa and Baa bonds rated by Moody's.

The main business cycle variable is real annual U.S. GDP growth (denoted GDPGR). Our large sample covers manufacturing and non-manufacturing firms, which justifies the use of a large aggregate indicator as opposed to a more narrow indicator like industrial production. In addition to our coincident macroeconomic indicator we use three leading indicators based on market yields of government and private debt instruments.

First, we use the change in the average annual spread between the 3-month commercial paper rate and the 3-month Treasury bill rate (DCPSPR), because it is considered as a predictor of future economic fluctuations. Specifically, downturns are generally preceded by a spike in the CP spread and recoveries by its tightening (see Friedman and Kuttner, 1991). A rationale for this property, besides default risk and monetary conditions, is companies' variability in cash needs over the business cycle. According to Friedman and Kuttner the CP spread can be viewed as a demand-driven phenomenon, resulting from companies' operating performance. An alternative view is that spikes in short therm financing costs (related to rising credit risk premiums) are also a signal of a general tightening of credit conditions, which forces companies to restrain some of their operations and therefore reduce their profitability (as noted by Bernanke, Gertler and Gilchrist, 1996).

For analogous reasons we include in our variables the change in the bond spread (DBSPR) calculated as the change of the average annual spread between seasoned Baa and Aaa bonds.

The third and last variable is the change in the average annual term spread between the 10-year Treasury note rate and the 3-month Treasury bill rate (DTSPR), following studies on the information content of the term spread with respect to future real economic activity (see Estrella and Hardouvelis (1991), and more recently Hamilton and Kim (2002)).

All spread variables are taken as changes in the annual average of weekly values. GDP growth is calculated as the rate of change of the real annual GDP. Given that these macro variables are highly correlated, we orthogonalize them in a triangular fashion. We start by taking GDPGR without changes. We then regress DCPSPR on GDPGR and a constant and we keep the residual as our next macro variable. We then regress DBSPR on GDPGR, DCPSPR

\footnotetext{
${ }^{2}$ Before 1997 we use the 3 -month prime commercial rate which includes financial and non-financial companies.
} 
and a constant, and again we keep the residual, etc. Finally we standardize all variables to zero mean and unit variance.

In the remainder of the paper the names GDPGR, DCPSPR, DBSPR, and DTSPR will refer to these orthogonalized and standardized variables. We plot the GDP growth and the unadjusted levels of spread variables on figure 1.

In figure 2 we plot the differenced spread variables before and after adjustment for correlation. We note that there is little change before and after the adjustment in the $\mathrm{CP}$ and the term spread variable. The bond spread variable keeps the general appearance, but with some discrepancies during the 1980s.

\subsection{Measuring financing constraints}

We measure financial constraints using the synthetic Whited and Wu (2006) index (WW) and four fundamentals-based proxies following Almeida, Campello and Weisbach (2004, ACW), Faulkender and Wang (2006), and Denis and Sibilkov (2010).

The index by Whited and $\mathrm{Wu}(2006)$ is defined as $\mathrm{WW}=-0.091 * \mathrm{CF} / \mathrm{TA}-0.062 *$ Divpos $+0.021 * \mathrm{LTD} / \mathrm{TA}-0.044 * \mathrm{LNTA}+0.102 * \mathrm{ISG}-0.035 \mathrm{SG}$ where CF is income before extraordinary items plus depreciation expense, TA is total assets, Divpos is a dummy variable for positive cash dividend, LTD is total long term debt, LNTA is the natural logarithm of total assets, ISG is 3-digit level industry sales growth, SG is the individual firm sales growth. Note that the initial index was estimated using quarterly data.

The fundamentals-based proxies of FC are:

- $\mathbf{P} / \mathbf{O}$ ratio measured as (Dividends + Repurchases)/Earnings before extraordinary items and interest.

- Size measured as Total assets.

- LT rating measured as an indicator of whether the firm has a S\&P long-term issuer rating. 
- ST rating measured as an indicator of whether the firm has a S\&P short-term issuer rating.

We follow ACW in defining firms with high and low financial constraints. For WW, P/O, and size we sort annually all firms based on each of the three variables. Financing constraints are increasing in the WW index and decreasing in $\mathrm{P} / \mathrm{O}$ and size. We define as high and low financing constraints the appropriate top/bottom three deciles in each annual cross-section.

For the rating variables we define as constrained firm-years without a valid non-default grade rating and with positive debt. Unconstrained firms are those that have a valid nondefault rating and positive debt. It is not obvious whether firms without a rating and without debt should behave as less constrained than firms without a rating with positive debt. Not having a debt could be a result of stricter internal policies. If this is the case, then this situation is equivalent to not being able to issue debt, i.e. being constrained. ACW briefly discuss the fact that these firms may be either constrained or unconstrained. Whenever we do regressions on pooled observations we will therefore only use an indicator variable for the unconstrained firms, which is less disputable. This is equivalent to a more conservative assumption that all firms that do not have a rating are constrained.

\subsection{Measuring market competition}

The most commonly used measure of the degree of product market competition (PMC) is the Herfindahl-Hirschman index (HHI) defined as the sum of the squared market shares of firms in the industry. The most common alternative to the $\mathrm{HHI}$ is the simple concentration ratio $\mathrm{C}(\mathrm{x})$ (the ratio of the $\mathrm{x}$ largest firms' market share to the overall market sales). There is a wide agreement that the HHI is an imperfect measure of concentration. For example it does not take into account regional concentration effects, and it cannot capture more complex market structures such as Stackelberg-like structures (see the discussion in Martin 1993, p. 167). In effect, intermediate HHI values of about 500 can be associated with very different levels of competitive structures. ${ }^{3}$

\footnotetext{
${ }^{3}$ Also note that the Department of Justice considers industries moderately concentrated above the value of 1000 and concentrated above 1800. See http://www.justice.gov/atr/public/testimony/hhi.htm (accessed
} 
We measure market competition using the annual fitted Herfindahl-Hirschman index by Hoberg and Phillips (2010) from their Web Data Library. ${ }^{4}$ These data are constructed by using the Census HHI of manufacturing industries and extending them to all 3-digit industries using the HHI calculated from public firms' sales in Compustat. This approach is a compromise between using only Census data (which are calculated only with a 5-year frequency and only covering manufacturing industries) and calculating HHI from Compustat data only, thus excluding all private firms (see the critique by Ali, Klasa and Yeung, 2009). Our measure of competition is PMC $=1-\mathrm{HHI}$, that we standardize to zero mean and unit variance. As a secondary measure, we define indicator variables for the top and bottom $30 \%$ observations based on the PMC variable.

We also use as a robustness check an individual measure of market power as in Peress (2010), the relative Lerner index (or the relative price-cost margin). The raw Lerner index is defined for each firm as Lerner $i t=\left(\right.$ Sales $\left._{i t}-\mathrm{COGS}_{i t}-\mathrm{SGA}_{i t}\right) /$ Sales $_{i t}$, where COGS is the Cost of goods sold and SGA is Selling, general and administrative expenses. We truncate the raw Lerner indexes at 0 , as negative values of the index have little theoretical foundations and we consider them to imply zero market power. The relative index is obtained by subtracting from the raw value the firm's SIC3 industry sales-weighted average. The relative Lerner variable has significant variability that might be a noisy measure. As in the previous case we construct indicator variables for the top and bottom 3 deciles and use these in our analysis.

To better understand the implications of using the HHI versus the alternative measure of market power we inspected at the 3-digit SIC level the relationship between the fitted HHI value and the intraindustry dispersion of individual firm market power. We measure the latter by the industry standard deviation of firms' raw Lerner indexes in a given year. As illustrated in figure 3, there is relatively little dispersion of firm Lerner indexes among the highly concentrated industries. On the other hand, the dispersion of firm Lerner indexes varies a lot at the lower end of the HHI. We note that some of this pattern is due to a lower number of firms in highly concentrated industries. The table 4 presents for the year 2005 industries with a HHI below

\footnotetext{
January 2010).

${ }^{4}$ http://www.rhsmith.umd.edu/industrydata/ (accessed November 2010).
} 
500 and with a dispersion of firm Lerner indexes at the high and low end. We can see that industries with a low dispersion of Lerner indexes (i.e. relatively equal distribution of market power) are mostly standardized products and services, with the exception of Newspapers. Conversely, industries with dispersed Lerner indexes (uneven distribution of market power) are industries with likely geographical, technological or variety-related concentration effects.

Given that our alternative measure of market power uses relative Lerner indexes, it will mostly pick up the variability of market power within these lower concentration/high dispersion industries, whereas industries with low dispersion of Lerner indexes will tend to generate firm observations with relative Lerner indexes closer to zero. Therefore, when we later use the relative Lerner index to measure market power, we will mostly check that our reasoning holds in these intermediate concentration industries.

Lastly, we note that the distribution of financing constraints across the corporate universe is not orthogonal to industry concentration. In fact, most measures of financing constraints are positively correlated with firm size (see discussion in Bernanke, Gertler, and Gilchrist (1996)). Small firms tend to be less well known, less transparent and more subject to agency costs. But firms in more concentrated industries tend to be larger, by definition of industry concentration.

We argue that financing constraints can coexist with concentrated markets (i.e. not all constrained firms are in competitive industries). We present in table 4 average proportions of firms with high financing constraints in industries with a Low, Medium and High concentration. As expected, the proportion of constrained firms seems to be negatively correlated with industry concentration for all constraints proxies except ST ratings. For example, for the WW index $37 \%$ of firm-years are deemed as constrained in low concentration industries, while only about $20 \%$ are deemed as constrained in concentrated industries. Although these results confirm a clear correlation between constraints proxies and concentration, we are reassured that there is still a significant number of constrained firms in highly concentrated industries.

The most interesting cases of coexistence of concentration with financing constraints are in moderate-to-high concentration industries. For example the Aircrafts and Parts industry $(\mathrm{SIC} 3=372)$ had a HH index of 1006 as of 1995. The main actors (Boeing, United Technologies, 
and Textron) all had assets in excess of $\$ 15$ billion at that time. But this industry also contained very small and likely financially more constrained firms such as EDAC Technologies, CADE Industries, and CPI Aerostructures, all with assets below $\$ 35$ million.

A second example is Household audio\&video equipment (SIC3=365) where the HH was 1057 as of 2005. The actors included the large Harman International with assets in excess of $\$ 2$ billion, medium-sized Universal electronics (\$146 million), as well as smaller Rockford Corp. (\$52 million) and Koss (\$29 million), both likely more constrained.

\section{Operating performance and the business cycle}

\subsection{Estimation method}

We estimate a simple model in which we regress firm profitability $\mathrm{ROA}_{t}$ (earnings before extraordinary items and interest divided by total assets) on (i) a set of macroeconomic variables, (ii) their interaction with measures of financing constraints and industry competition (where applicable), (iii) a set of firm controls, (iv) a linear trend and a constant.

All firm variables are lagged and they control for the expected profitability level. These firm-level variables include similar variables as those used by Fama and French (2000) for estimating expected profitability, namely the market-to-book ratio of assets (M/B Assets), common dividends and repurchases divided by book equity $((\mathrm{D}+\mathrm{Rep}) / \mathrm{BE})$, and a dummy variable indicating nonzero common dividends during the previous year (DDUM). We also add a variable measuring capital intensity calculated as property, plant and equipment divided by total assets $(\mathrm{K} / \mathrm{A})$, and an investment intensity variable measured by capital expenditures to total assets $(\mathrm{I} / \mathrm{A})$. We include a linear trend to capture the changes in average profitability in the cross-section of listed firms.

We estimate the following equation using a fixed firm effect estimator with firm-clustered standard errors:

$$
\mathrm{ROA}_{i t}=\alpha+\sum_{j=1}^{4} \beta_{j} \operatorname{MacroVar}_{t}^{j}+\sum_{k=1}^{5} \gamma_{k} \operatorname{FirmVar}_{i t-1}^{k}+\operatorname{Trend}_{t}+\epsilon_{i t}
$$


where the MacroVar set includes GDPGR, DCPSPR, DBSPR, and DTSPR and the FirmVar set includes the $\mathrm{M} / \mathrm{B}$ of assets, $\mathrm{D} / \mathrm{BE}, \mathrm{DDUM}, \mathrm{K} / \mathrm{A}$ and $\mathrm{I} / \mathrm{A}$.

This equation is first estimated without further interaction terms, to serve as baseline. In subsequent sections we interact the MacroVar set with lagged measures of financing constraints and/or product market competition, as defined in sections 3.3 and 3.4. This specification is similar to the reduced form specification used by Sharpe (1994) for analyzing firm employment growth. We will therefore be able to check whether measures of constraints and/or concentration significantly affect the sensitivity to the business cycle variables.

\subsection{Results on market competition}

In this section we first confirm one of the building blocks of this paper, namely that that firms in concentrated industries resist better to aggregate fluctuations (hypothesis H1). We will estimate the following modification of equation (1) including the levels of PMC as of the previous year, and MacroVar-PMC interactions:

$$
\text { (1) + PMC + MacroVar-PMC interactions }
$$

As two alternative specifications, we will also estimate a version that includes lagged indicator variables for high (Hi) and low (Lo) product market competition/relative Lerner index, and the interactions of MacroVar with the indicator variables:

$$
\text { (1) + PMC indicators + MacroVar-PMC indicator interactions }
$$

The first column of table 5 presents coefficients on the macro variables in the baseline case without concentration measures. The coefficients are strongly statistically significant except for DCPSPR. The GDP growth variable has a significantly positive influence on operating profitability. As a rule of thumb, a one standard deviation positive shock in real GDP growth translates into 0.36 percentage points of additional profitability. The change in the bond spread has a significantly negative effect on profitability. An unexpected one standard deviation 
increase in the bond spread leads to a fall of 0.37 percentage points of average profitability. Lastly, the term spread also has a significant negative effect on firm profitability and is the strongest in magnitude. A one standard deviation unexpected increase in the term spread is associated with 0.61 points less profitability.

Column (2) shows that interacting the macro variables with the PMC levels significantly alters the picture. A one standard deviation increase in the level of competition increases the sensitivity to the GDP growth by about one third. Moreover, PMC strengthens also the sensitivity to the bond spread (by more than one half per one standard deviation of PMC) and to the term spread (by more than one third per SD). These results support our underlying hypothesis of insulation against aggregate shocks.

We present in Column (3) interactions with dummy variables for high and low PMC. These result suggest that the effects of the PMC levels presented in Column (2) seem to be driven by the low end of the PMC variable (i.e. concentrated industries), as it is mostly the Lo dummy that has a significant coefficient in this specification. Concentrated industries seem to be more than one half less sensitive to the GDP growth and the term spread, and seem to be quasi-insensitive to the bond spread.

Column (4) presents results using interactions with a dummy variable for high and low relative Lerner index. As we discussed in section 3.4, this measure of market power picks up mostly the variability in the intermediately concentrated industries with a high dispersion of individual firm Lerner indexes. Therefore this approach is a complement to the previous two cases. The results are qualitatively similar to the previous case. Firms with a high market power are more than one half less sensitive to the GDP and about one quarter less sensitive to the term spread. Firms with a low market power are more than twice as much exposed to the term spread. There is a significant positive coefficient on the CP spread on both high and low interaction coefficients.

The explained variability in all specifications is about 7 to 8 per cent. We note that these $\mathrm{R}$-squared exclude the variability captured by the firm fixed effects (the fixed effect represents about $75 \%$ of the total error variance), therefore the overall explained variability is actually 
much higher.

We summarize this section by stating that our results speak in favor of the hypothesis that imperfectly competitive industries benefit from a significant insulation from aggregate shocks. Firms in concentrated industries seem to be less exposed to both the coincident business cycle variable, as well as to leading indicators.

\subsection{Results on financing constraints}

\subsubsection{Standalone specification}

We first proceed to the analysis of the effect of financing constraints without controlling for industry competition. The studied specification will be analogous to the previous case. We estimate the equation using lagged indicator variables for high $\left(\mathrm{Hi}_{\mathrm{FC}}\right)$ and low $\left(\mathrm{LoFC}_{\mathrm{FC}}\right)$ financing constraints based on the WW index, the payout ratio, size, and LT and ST ratings, and their interactions with the macro variables:

$$
\text { (1) + FC indicators + MacroVar-FC indicator interactions }
$$

In table 6 we summarize results for five different proxies of financing constraints (note that for the two ratings proxies there are only dummies for low constrained firms due to reasons discussed in the last paragraph of section 3.3).

The sensitivity to GDP is significantly lower for firms facing low constraints, for all proxies except the WW index which is only significant at the $10 \%$ level. Depending on the proxy, unconstrained firms are about $30 \%$ to $70 \%$ less sensitive to GDP growth than the average firm. Constrained firms have either an insignificant negative interaction coefficient (WW and size), or a positive coefficient significant at the $10 \%$ level (P/O ratio).

The results on the bond spread are the most clear-cut. For all our proxies unconstrained firms are less exposed to unexpected changes in the bond spread: on average about $50 \%$ less than average firms. On the other hand, constrained firms are significantly more sensitive to this variable for two out of three proxies used, and the coefficient is negative on the third one. 
There is little significance on the CP spread interaction terms. The term spread interaction coefficients are only significant for one proxy, the $\mathrm{P} / \mathrm{O}$ ratio.

In all cases, the model explains about $6 \%$ to $7 \%$ of the variance of the dependent variable, excluding the firm fixed effects contribution. The RMSE, not presented in the table, is about 0.09 to 0.10 (note that the SD of the dependent variable is about 0.14 ).

To sum up, using various proxies of financing constraints we conclude that constrained firms' operations are more sensitive to the overall business cycle, being affected more by both the coincident indicator as well as one leading indicator, the bond spread. Our results are apparently consistent with the flight to quality effect of Bernanke, Gertler and Gilchrist (1996) where constrained firms tend to suffer early in economic slumps from a tightening of credit conditions.

\subsubsection{Specification controlling for market competition}

We will now attempt to analyze the hypothesis H3, which claims that the financial acceleratorlike effect documented in the previous section is strongest in competitive industries. We will estimate an equation that controls for financing constraints, product market competition, and their interactions. We will use the PMC levels as a measure the level of competition.

$$
\begin{aligned}
& (1)+\text { FC indicators + PMC + MacroVar-PMC interactions } \\
& + \text { MacroVar-FC indicator interactions } \\
& + \text { MacroVar-FC indicator-PMC interactions }
\end{aligned}
$$

Table 7 shows results for this combined specification. We see that the first eight rows of the table are qualitatively and quantitatively similar to the specification with competition interactions only (presented in table 5, column (2) ): firms in concentrated industries have a better aggregate shocks resistance.

Simple interaction terms with financing constraints proxies are less significant than in the standalone specification in table 6. Low constrained firms have a negative interaction coefficient 
on GDP, but significant only for two out of five proxies. The bond spread interaction effect survives in this specification: all five coefficients are significantly positive for the low constraints dummy, and all coefficients are positive (one significantly) on the high constraints dummy. The Term and CP spread coefficients show no clear patterns.

The parameters of interest are on the cross interaction terms containing both the competition and the constraints variables. The cross interaction term of Low constraints with PMC is mostly positive and significant in two out of five cases. The cross term of High constraints and PMC is negative and significant in two out of three cases. This means that constrained firms tend to benefit relatively more from the macro-protection effect of industry concentration. Conversely, constrained firms are the most exposed to aggregate shocks in highly competitive industries. This picture is even more clear with the cross terms on the Bond spread. Low constraints cross terms are all significantly negative at least at the $10 \%$ level, while High constraints terms are all positive, one significant and two just below the $10 \%$ significance level. Again constrained firms tend to benefit more from the insulation from aggregate shocks due to the concentration of their industry. Similar but less straightforward patterns can be seen on the Term spread cross coefficients.

In these specifications, the model explains 6 to $7 \%$ of the variance of the dependent variable, excluding the fixed effect's contribution. The RMSE (not presented) is in the interval 0.0930.098, therefore about one-third of firm profitabilty's standard deviation is captured by the model.

This section provided significant evidence in favor of the hypothesis H3: financing constraints seem to have stronger real effects on the operating performance of companies in the most competitive industries. Put differently, the macro-insulation benefit of concentration is higher for firms deemed as constrained using a number of common proxies of financing constraints. 


\section{Other real effects of financing constraints}

In this section we will inspect whether the previously discussed results concerning operating performance have their impact on firm behavior, in particular in terms of investment and employment. In effect, the main implication of the financial accelerator as presented in Bernanke et al. (1996) is that financially constrained firms subject to a flight to quality are forced to restrain their investment more than other firms, thereby further contributing to the aggregate economic slowdown and effectively contributing to the depth of the recession.

We will estimate an enriched version of an investment model where we include a macro variable and its interaction with market concentration. As it is standard in the investment literature we will estimate this equation on subsamples based on various financial constraints proxies (see for example Gilchrist and Himmelberg (1995)). The estimated specification is:

$$
\operatorname{Inv}_{i t}=\alpha+\left(\beta+\delta \times \mathrm{PMC}_{t-1}^{\mathrm{SIC} 3}\right) \times \mathrm{GDPGR}_{t}+\sum_{k=1}^{6} \gamma_{k} \operatorname{FirmVar}_{i t-1}^{k}+\gamma_{7} * \mathrm{PMC}_{t-1}^{\mathrm{SIC} 3}+\epsilon_{i t}
$$

In the following subsections Inv will be one of three investment rates (in physical capital, in net working capital, in inventories) or the employment growth rate. The set of lagged firm variables FirmVar includes the M/B ratio of assets, cash flow measured as the operating income before depreciation divided by assets, capital intensity measured as PPE/Assets, size measured as the log of assets, a dividend payer dummy, and previous year's industry sales growth.

\subsection{Fixed investment}

We first present our results for equation 6 applied to investment in physical capital, defined as the ratio of capital expenditures to net property, plant and equipment. We exclude irrelevant firms operating with very low physical capital, i.e. whose PPE/Assets ratio is lower than $5 \%$.

The first observation from table 8 is that the sensitivity of investment to GDP is clearly higher for firms with high constraints. For unconstrained firms a one standard deviation increase in GDP is associated with a $0.57-1.08$ percentage point increase in the investment 
rate, depending on the proxy used. For constrained firms this increase in GDP will lead to a 0.99-1.50 percentage point increase in investment.

A second observation is that the interaction of GDP with PMC is positive in all cases, suggesting that industry competition increases the macro sensitivity of firm investment. However the coefficients are only significant in the high constraints subsample, and only for the first three proxies. Judging by the size of the constrained subsample for the rating-based proxies, this absence of significance could be due to the crudeness of these two constraints proxies. In the three cases where the coefficient is significant, it has economically significant value. A one standard deviation increase in PMC increases the GDP sensitivity by between $30 \%-50 \%$.

We conclude that we found partial evidence for an interaction effect of financing constraints and industry concentration in the cyclical sensitivity of firm investment. As in the section on operating performance, we find that industry concentration benefits constrained firms more than unconstrained firms.

\subsection{Net working capital and inventories}

In this section we apply equation 6 to investment in net working capital defined as the change in net working capital divided by PPE. Net working capital (NWC) has been analyzed in the context of firm investment because it serves as a buffer when financing becomes scarce (as shown by Fazzari and Petersen (1993)). In effect, NWC just like any other component of operating assets has to be financed in the balance sheet of the firm. When available finance becomes limited, particularly for the more constrained firms, firms face a trade-off when allocating funds to various asset components. Fazzari and Petersen argue that firms can adjust NWC investment at a lower cost than fixed investment and therefore NWC is used as a liquidity buffer. The business cycle variability of NWC could thus reveal interesting patterns, complementary to those seen on fixed investment in the previous section.

We define net working capital as current assets minus cash minus current liabilities. We exclude cash because cash plays an important role for investment policy, in particular for constrained firms (see Denis and Sibilkov (2010)). Again we exclude firms having a low physical 
capital ratio (PPE/Assets ratio below 5\%).

Table 9 confirms that the NWC investment sensitivity to economic conditions varies strongly with the financing constraints status. For low constraints firms, the sensitivity is relatively low and significant for only two out of five proxies. For the high constraints subsample, the sensitivity to GDP is significantly positive. A one standard deviation negative shock on economic activity reduces NWC investment by 3.4-5.5 percentage points. The interaction effect of GDPGR with PMC seems to be mostly positive, but it is only significant in one single case- high constraint firms measured by the $\mathrm{P} / \mathrm{O}$ proxy.

Next, we focus our attention on a subset of NWC: inventories. This asset has a particular role in macroeconomics, because changes in inventories constitute an important source of aggregate economic growth variability. Gertler and Gilchrist (1994) point out differences in the behavior of inventories in small manufacturing firms relative to large firms, the former accounting for a large part of the variability of the aggregate inventory changes.

We also focus specifically on investments in inventories, defined as the change in inventories divided by PPE (results not presented, but available upon request). We note that inventory investment is pro-cyclical in all three subsamples, but the effect is strongest in the constrained subsample. As in the NWC case, the coefficient on the PMC interaction term is positive and strongest in the constrained subsample, but is significant in only one case.

Our results on NWC and inventories confirm their role of a buffer asset: the sensitivity of this item to aggregate economic activity is considerably higher than the sensitivity of fixed investment. Moreover, constrained firms' NWC investments seem to be more sensitive to the aggregate shock by a factor of at least 2 compared to unconstrained firms. The interaction of constraints with product market competition is not significant.

\subsection{Employment}

The last real effect that we will analyze is employment growth. Sharpe (1994) shows that the aggregate sensitivity of firm employment to the business cycle is higher for small firms and for firms with a high leverage. As we discussed in section 3.3 size is a common proxy 
for financing constraints. Compared to Sharpe (1994) our specification controls for product market competition in addition to constraints.

We include in our analysis only firms which have had an asset growth rate within the ($50 \%,+100 \%$ ) range, to mitigate the effect of firm-years with significant corporate events such as mergers and spin-offs. Table 10 suggests that there is a macro-sensitivity differential between the High and Low constraints subsamples. Low constraint firms reduce their employment by $1.2 \%-2.5 \%$ for a one SD decrease in the GDP, whereas constrained firms slash employment by $2.8 \%-3.1 \%$.

Interactions with PMC have neither a significant coefficient, nor stable signs. Constrained firms operating in concentrated industries do not seem have a lower employment sensitivity to the aggregate cycle.

We summarize this section by noting that financially constrained firms' investment in fixed assets and working capital and their employment appear more sensitive to the business cycle compared to unconstrained firms. Industry competition strengthens this effect only on fixed investment.

\section{Some asset pricing results}

Previous sections show that financially constrained firms are more exposed to aggregate shocks. This fundamental risk is particularly high if they operate in highly competitive industries. In this section we show that stock prices do not completely reflect these differences in fundamental risk.

We start by merging our fundamentals data with CRSP stock returns. We use all firms that both satisfy our fundamentals data requirements (see section 3) and have valid CRSP returns data. At the end of June of each year $t$ we take the year t-1 sorts from the fundamentals dataset and we construct portfolios based on PMC and FC top/bottom terciles. We use this portfolio structure to calculate July t to June $t+1$ returns. We use three proxies for FC: the WW index, the payout ratio, and size (total assets). We end up with three sets of nine 
double-sorted portfolios and we calculate their value-weighted monthly excess returns.

We regress portfolio excess returns on three Fama-French factors and the momentum factor. ${ }^{5}$ In table 11 we present time-series regression estimates on the period July 1977 to December 2009 .

In Panel A (WW index) we observe that at low and medium levels of market competition, unconstrained firms have the lowest market beta, as expected. For high levels of competition, however, market beta differs little for different levels of FC. We also note that market beta is highest for medium FC firms at all levels of competition, although the difference is small for medium and high PMC levels. This latter result might be surprising at first. But note that the difference in risk between medium and high FC firms is captured instead by the SMB factor. Indeed, high FC firms map strongly on the size factor.

The most interesting observation in Panel A is that low constraints firms in medium and highly competitive industries earn a significant positive abnormal return. The High PMC/Low FC portfolio earns about 26bp monthly abnormal return (about $3.1 \%$ annualized). This is surprising given our evidence that these companies bear significantly less fundamental risk compared to highly constrained firms. Stock prices do not seem to reflect this fundamental risk differential.

Panel B (payout ratio) presents an even clearer picture. Market beta is generally increasing in both PMC and FC. Moreover, additional risk exposure of highly constrained portfolios is mapped on the SMB factor. Again, unconstrained firms in medium and highly competitive industries earn a significant abnormal return of 19bp (2.3\% annualized) and 40bp (4.9\% annualized), respectively.

In Panel C (size) the overall picture remains similar to Panel A. Market beta is not necessarily monotonous in FC, in particular in the highly competitive portfolios. But the SMB factor mappings capture a large part of overall risk of high FC portfolios. Most importantly, the Low FC firms earn again significant positive abnormal returns in medium and highly competitive industries (16bp and 24bp, respectively).

We investigate further the abnormal returns patterns by running moving window time-

\footnotetext{
${ }^{5}$ We use factor data from Kenneth French's webpage.
} 
series regressions of portfolio returns on the same set of four factors. We present in figure 4 abnormal returns and their t-stats from 48-month moving window regressions of four corner portfolios corresponding to combinations of High/Low FC and High/Low PMC.

First, for all three FC proxies the High FC/High PMC portfolio earned mostly negative abnormal returns over the second half of the 1980s, marked by the beginning of the savings and loan crisis and the stock market crash of 1987. The period 1994-95 (Fed tightening, bond market decline and rising yield volatility) through 1997 (Asian crisis) was also a period of mostly significant negative abnormal returns for this portfolio, but only based on the WW and Size proxies. The first half of the 2000s is the only period of positive abnormal returns, significant only when using the WW and P/O proxies. The 2007-2009 crisis brought again some negative abnormal returns.

The High FC/Low PMC portfolio had also negative alphas during these periods of distress, namely the second half of the 1990s and the 2007-09 crisis. But there were also periods of significantly positive returns: the first half of the 1980s and the early 1990s.

The Low FC/High PMC portfolios earned positive alphas during the 1997 Asian crisis period with a peak in early 1998 for all three FC proxies. Similarly, these companies earn positive returns in the post-recession periods of 2002-03, and 2009. The only instance of significant negative returns is the 1986 period.

Last, the Low FC/Low PMC portfolio abnormal returns are clearly lower in magnitude and only significant at times. For example, alphas were significant during the 2007-09 crisis period.

The moving window analysis sheds some light on the positive abnormal returns of low constraints firms in medium and highly competitive industries observed in table 11. Unconstrained firms in highly competitive industries tend to benefit from post-downturn conditions when arguably their constrained rivals are still experiencing difficulties (as documented in previous sections). However, this fact is not sufficiently reflected in valuations and unconstrained firms generate positive abnormal returns in those periods. This finding is new and is complementary to results on the effect of product market competition on stock returns by Hou and Robinson 
(2006).

Also, the abnormal negative returns of constrained firms in crisis periods indicates that at normal times their stock prices do not reflect their financial 'vulnerability'. This finding could partly explain why previous studies find that a financing constraints factor in stock returns earns a negative (Lamont, Polk, and Saá-Requejo 2001) or a positive but insignificant risk premium (Whited and Wu 2006).

\section{The effect of financing constraints on competitive mechanisms}

\subsection{A simple mean reversion model}

Up to this point, we have studied how ex ante measures of competition intensity affect the real effects of financing constraints. In this section we will look at how ex ante measures of financing constraints at the firm and industry level affect competitive mechanisms.

To address this question we will analyze how financing constraints affect the cross-sectional mean-reversion mechanism of firm profitability. Following Fama and French (2000, hereinafter FF) we estimate a simple partial adjustment model of mean-reversion of profitability. In their paper FF propose a two step method. In the first step they estimate on each year's cross-section the expected profitability for each firm based on three variables: M/B of assets, dividends to book equity and a dummy indicating zero dividends. ${ }^{6}$ As a second step, the authors estimate an equation where the change of profitability for a firm in year $t$ is explained by the lagged profitability change and by the difference between observed and expected profitability in $t-1$. The main FF specification is somewhat disputable, given that expected profitability is linked to the $\mathrm{M} / \mathrm{B}$ ratio of assets. In effect, such a specification allows the expected profitability in subsequent years to "revert" to effective profitability instead of the seeing the effective number reverting to its expectation (as we implicitly expect in the notion of mean-reversion). If a firm earns abnormal levels of profitability in year $t$, the market can interpret this surprise as the "new normal": M/B increases and therefore next year's expected profitability increases as well. This

\footnotetext{
${ }^{6}$ Note that we include very similar variables as individual firm controls in our regressions in section 4 , except that we use lagged values.
} 
specification therefore jointly tests a mean-reversion of profitability and a correct treatment of fundamental information by the markets. The authors find a rate of mean reversion in this specification at about $38 \%$ a year.

FF include also a more robust specification in which profitability is assumed to meanrevert to a common cross-sectional mean. In this setting the mean-reversion coefficient is also significant, though lower, at about $30 \%$ a year. It seems normal that in this case the estimated mean-reversion rate is lower, because we capture the pure mean-reversion of effective profitability to a common mean.

We specify a model similar to the FF's second specification, except that we explicitly include the cross sectional average profitability in the previous year. The baseline model is

$$
\mathrm{ROA}_{i t}-\mathrm{ROA}_{i t-1}=\alpha+\beta\left(\mathrm{ROA}_{i t-1}-\mathrm{ROA}_{t-1}^{\mathrm{agr}}\right)+\gamma\left(\mathrm{ROA}_{i t-1}-\mathrm{ROA}_{i t-2}\right)+\epsilon_{i t}
$$

where $\mathrm{ROA}_{i t}$ is earnings before extraordinary items and interest divided by assets and where $\mathrm{ROA}_{t}^{\text {agr }}$ is the asset-weighted average ROA in the cross-section of all firms.

We then include interaction mean-reversion terms controlling for financing constraints at the firm and industry level:

$$
\begin{aligned}
\mathrm{ROA}_{i t}-\mathrm{ROA}_{i t-1} & =\alpha+\left(\beta+\delta^{\mathrm{Lo}} \times \mathrm{Lo}_{\mathrm{FC} t-1}+\delta^{\mathrm{Hi}} \times \mathrm{Hi}_{\mathrm{FC} t-1}+\delta^{\% \mathrm{Hi}} \times \% \mathrm{Hi}_{\mathrm{FC} t-1}\right) \\
& \times\left(\mathrm{ROA}_{i t-1}-\mathrm{ROA}_{t-1}^{\mathrm{agr}}\right)+\gamma\left(\mathrm{ROA}_{i t-1}-\mathrm{ROA}_{i t-2}\right)+\epsilon_{i t}
\end{aligned}
$$

where $\mathrm{LoFC}$ (HiFC) is an indicator variable of the bottom (top) $30 \%$ observations based on the constraints proxy in the previous year, and where \% Hi is the proportion of HiFC firms within the SIC3 industry in the previous year. Equation (8) is slightly modified for the rating-based proxies, where we only use indicators for low constrained firms (see section 3.3 for a discussion of this choice).

We estimate these equations using the Fama and MacBeth (1973) method and we present the results in table 12. The baseline mean-reversion coefficient of $26.9 \%$ per year in column (1) is reasonably close to the value of about 30\% found by Fama and French (2000) on an 
earlier sample period. Note that autocorrelation in the year-by-year slope estimates is not being corrected for in our tables, which means that t-statistics are overestimated. If we had a sufficiently long time series of these slope estimates, we would be able to estimate reliable autocorrelation estimates and calculate adjusted SEs by the Newey-West technique. Since this is not the case, to infer significance we follow Fama and French (2000) and require somewhat higher t-statistics for significance. FF estimate that with an autocorrelation of 0.5 , the SEs should be increased by about $40 \%$, therefore the threshold for t-stats should be at about 2.8 instead of the commonly used value of 1.96 .

In columns (2) to (6) we use five different proxies for financing constraints. We find partial evidence that firm-level constraints affect the mean-reversion rate of firm profitability: for two constraints proxies (WW index and $\mathrm{P} / \mathrm{O}$ ratio), the difference between constrained and unconstrained firms is significant and suggesting that constrained firms revert to the mean faster than unconstrained firms. The evidence is more clear-cut for the industry-level constraints: the percentage of constrained firms significantly reduces the mean reversion rate in all three cases. Increasing the percentage of constrained firms within an industry by 50 percentage points reduces the mean reversion rate by about 12 percentage points. We note however that the percentage of unconstrained firms in the two ratings-based cases has the expected negative coefficient only for LT ratings and the average $t$ statistic is below our increased hurdle value of 2.8 in both cases.

\subsection{Two-level mean-reversion}

When looking at the specification of equation (7) one could argue that the implicit assumption of mean-reversion towards one common average profitability for all firms is implausible. The most obvious argument is that one common expected profitability does not take into account differences in risk across industries. A similar critique can be made based on differences in technology, the level of intangible assets (human capital, tacit knowledge, brand value, reputation) etc.

To address this issue, we improve somewhat the specification by including a two-level mean- 
reversion mechanism. The first level is the mean reversion of firm profitability to the industry mean. The second level is the mean-reversion of the industry mean to the aggregate mean. If the above critique is justified, we should only find evidence for the first level of mean reversion. Specifically, we estimate in the baseline case the equation

$$
\begin{aligned}
\mathrm{ROA}_{i t}-\mathrm{ROA}_{i t-1} & =\alpha+\beta^{1}\left(\mathrm{ROA}_{i t-1}-\mathrm{ROA}_{t-1}^{\mathrm{SIC} 3}\right)+\beta^{2}\left(\mathrm{ROA}_{t-1}^{\mathrm{SIC} 3}-\mathrm{ROA}_{t-1}^{\mathrm{agr}}\right) \\
& +\gamma\left(\mathrm{ROA}_{i t-1}-\mathrm{ROA}_{i t-2}\right)+\epsilon_{i t}
\end{aligned}
$$

where $\mathrm{ROA}_{t}^{\mathrm{SIC} 3}$ is the asset-weighted average profitability in the SIC3 industry. The change in firm profitability can therefore be due to either the previous year's difference between the firm and its industry mean, or between the previous year's industry mean and the aggregate mean.

Analogously, the two-level specification controlling for financing constraints is

$$
\begin{aligned}
\mathrm{ROA}_{i t}-\mathrm{ROA}_{i t-1} & =\alpha+\left(\beta+\delta^{\mathrm{Lo}} \times \mathrm{Lo}_{\mathrm{FC} t-1}+\delta^{\mathrm{Hi}} \times \mathrm{Hi}_{\mathrm{FC} t-1}+\delta^{\% \mathrm{Hi}} \times \% \mathrm{Hi}_{\mathrm{FC} t-1}\right) \\
& \times\left(\mathrm{ROA}_{i t-1}-\mathrm{ROA}_{t-1}^{\mathrm{SIC} 3}\right) \\
& +\left(\lambda+\kappa^{\mathrm{Lo}} \times \mathrm{Lo}_{\mathrm{FC} t-1}+\kappa^{\mathrm{Hi}} \times \mathrm{Hi}_{\mathrm{FC} t-1}+\kappa^{\% \mathrm{Hi}} \times \% \mathrm{Hi}_{\mathrm{FC} t-1}\right) \\
& \times\left(\mathrm{ROA}_{t-1}^{\mathrm{SIC} 3}-\mathrm{ROA}_{t-1}^{\mathrm{agr}}\right)+\gamma\left(\mathrm{ROA}_{i t-1}-\mathrm{ROA}_{i t-2}\right)+\epsilon_{i t} .
\end{aligned}
$$

Table 13 shows results based on the two-level specification. The results at the first level (firm vs. industry) are qualitatively similar to the simple case. Individual financing constraints status seems to be relevant only in some cases (WW and $\mathrm{P} / \mathrm{O}$ ). The significant negative coefficient on the LoFC term for LT ratings is surprising as it suggests that low constraints firms seem to revert faster than other firms. The percentage of constrained firms has a significantly positive coefficient in all three cases (WW, $\mathrm{P} / \mathrm{O}$, size), and the percentage of unconstrained firms is negative for LT ratings although the average t-stat is still below our conservative threshold of 2.8 .

The picture is completely reversed at the second level (industry vs. aggregate): individual constraints status seems to be much more relevant here, with all coefficients having the same 
sign across all FC proxies, and with much higher average t-stats. On the other hand, the percentage of constrained firms in the SIC3 industry does not seem to be relevant as no average t-stat is above our threshold of 2.8 .

In summary, the two-level specification confirmed that profitability mean-reversion is happening at both the intra-industry and the inter-industry levels. We further confirmed that the proportion of constrained/unconstrained firms within the industry seems to be an important determinant of intra-industry profitability mean-reversion.

These regularities are not taken into account by market valuations. In table 14 we construct double sorted portfolios on (i) the relative firm profitability with respect to the profitability of its SIC3 industry, and (ii) on the industry percentage of financially constrained firms within the SIC3 industry. We that abnormally profitable firms earn alphas of about 20-29 bp per month if a high percentage of their rivals are financially constrained. The alphas are small and not significant for abnormally profitable firms if their industries have few constrained firms.

\section{Robustness}

Besides having used five different proxies for financing constraints previously employed in the literature, we have also tried several robustness checks for our results. First, we have employed an alternative specification for the interaction effect of financing constraints and market concentration on the business cycle sensitivity of operating profitability. Instead of including firm level proxies of lagged profitability we use lagged values of profitability. We use three lagged levels of ROA. Due to known issues with lagged dependent variables in panel data, we estimate this equation following Arellano and Bond (1991) with a difference GMM estimator (instrumenting with four lags of endogenous variables, collapsed). The MacroVar set includes the same four macro variables as in section 4. The statistical properties of this specification are improved when we include firm variables that likely affect deviations from a simple autoregressive specification (we use lagged changes in the fixed investment rate and in advertising expense). We capture the effect of financing constraints by estimating the equation on subsamples of Low, Medium, and High financing constraints. The results (not 
reported) strongly support our main set of results. The PMC interaction terms with GDPGR and DBSPR for the Low FC subsample are relatively low and sparsely significant. The same interaction terms on the High FC subsample are both statistically and economically significant.

Sharpe (1994) notes that using an aggregate economic variable on firm-level data could be problematic due to different industry exposure to macroeconomic conditions. As a robustness check he proposes to use industry-year specific dummy variables. We construct twelve industry groups based on the 12 Fama-French portfolios and create a dummy for each industry-year. ${ }^{7}$ The results (not reported) on fixed investment sensitivity are even stronger than in the general case: the interaction variable of PMC with GDPGR is significant for constrained firms using all five financing constraints proxies, while it is economically and statistically not significant for medium and low constrained firms.

The underlying idea of of this paper stating that financing constraints should affect more firms in competitive industries relies strongly on the assumption that firm cash flows are strongly correlated with the business cycle in the first place. Therefore, for industries whose cash flows covary little with the business cycle, the additional benefit of a concentrated market (providing insulation against aggregate shocks) should be less important. We follow Sharpe (1994) and Campello (2003) in separating industries into highly correlated ("durables"), weakly correlated ("non-durables"), and others ("non-manufacturing"). Our results on the sensitivity of operating profitability to GDP and bond spread shocks survive qualitatively in the durables subsample, with a loss of significance for some proxies. The results survive partially in the non-manufacturing subsample. The non-durables subsample completely loses significance on the GDP cross interaction terms, as expected due to a low correlation of cash flows with the economic cycle in these industries. On the other hand, the Bond spread effect survives even in the non-durables industries.

Lastly, we check whether our results are not driven by the recent crisis. Our results remain broadly unchanged if we exclude the 2007-2009 period.

\footnotetext{
${ }^{7}$ We use industry classification data from Kenneth R. French's data library.
} 


\section{Conclusion}

In this paper we studied the interactions of product market competition and financing constraints. The two research paths in the financing constraints literature, namely that of investment cash-flow sensitivities and that of financial accelerator, point to a vicious circle effect of financing constraints during economic downturns. Specifically, a constrained firm must rely on its internal funds exactly when cash flows are depressed, forcing it to a stronger reduction of operations and investment, further depressing internal funds etc. We argue that competitive industries undergo the strongest shock to cash flows at the onset of a downturn, thereby strengthening the adverse effect of financing constraints during the slowdown.

We find significant support for our hypothesis in the analysis of operating profitability of firms. The effects of macro variables on the operating performance of a constrained firm are stronger if the firm operates in a competitive industry. Stated differently, financially constrained firms tend to benefit relatively more from the insulation effect of a concentrated product market.

We confirm that financing constraints have significant real effects on the business cycle sensitivity of corporate investment and employment to the business cycle. In fixed investment data we find an amplifying effect of product market competition on the effects of financing constraints. On the other hand, investments in net working capital and employment growth do not seem to be subject to a similar amplification effect.

In our asset pricing tests we find that stock prices do not completely take into account these differences in fundamental risk. Specifically, unconstrained firms operating in competitive industries earn abnormal positive returns, particularly during periods of economic and financial distress.

Lastly, we show that financing constraints affect competitive mechanisms within industries. We find support for the hypothesis that the average level of financing constraints in an industry tends to reduce the intraindustry mean-reversion of firm profitability. Stock prices do not integrate this fact. Firms with a high profitability relative to their SIC3 industry profitability earn positive alphas, but only if a high proportion of their rivals are financially constrained. 


\section{References}

Ali, A., S. Klasa, and E. Yeung (2009): "The Limitations of Industry Concentration Measures Constructed with Compustat Data: Implications for Finance Research," The Review of Financial Studies, 22(10), 3839-3871.

Almeida, H., M. Campello, and M. S. Weisbach (2004): "The Cash Flow Sensitivity of Cash," Journal of Finance, 59(4), 1777-1804.

Arellano, M., and S. Bond (1991): "Some Tests of Specification for Panel Data: Monte Carlo Evidence and an Application to Employment Equations," Review of Economic Studies, 58(2), 277-297.

Bernanke, B., M. Gertler, and S. Gilchrist (1996): "The Financial Accelerator and the Flight to Quality," Review of Economics and Statistics, 78(1), 1-15.

Bils, M. (1987): "The Cyclical Behavior of Marginal Cost and Price," American Economic Review, 77(5), 838-855.

CAmpello, M. (2001): "Capital structure and product markets interactions: evidence from business cycles," Journal of Financial Economics, 60, 3-43.

Campello, M., and Z. Fluck (2006): "Product Market Performance, Switching Costs, and Liquidation Values: The Real Effects of Financial Leverage," Working paper.

Campello, M., J. R. Graham, and C. R. Harvey (2010): "The real effects of financial constraints: Evidence from a financial crisis," Journal of Financial Economics, 97, 470-487.

Chevalier, J. A., And D. S. Scharfstein (1996): "Capital-Market Imperfections and Countercyclical Markups: Theory and Evidence," American Economic Review, 86(4), 703725 .

Denis, D. J., And V. Sibilkov (2010): "Financial Constraints, Investment, and the Value of Cash Holdings," Review of Financial Studies, 23(1), 247-269.

Domowitz, I., R. G. Hubbard, and B. C. Petersen (1986): "Business cycles and the relationship between concentration and price-cost margins," Rand Journal of Economics, $17(1), 1-17$.

Estrella, A., and G. A. Hardouvelis (1991): "The Term Structure as a Predictor of Real Economic Activity," Journal of Finance, 46(2), 555-576.

Fama, E. F., and K. R. French (2000): "Forecasting Profitability and Earnings," Journal of Business, 73(2), 161-175.

Faulkender, M., And R. Wang (2006): "Corporate Financial Policy and the Value of Cash," Journal of Finance, 61(4), 1957-1990.

Fazzari, S. M., R. G. Hubbard, and B. C. Petersen (1988): "Financing Constraints and Corporate Investment," Brookings Papers on Economic Activity, 1988(1), 141-206. 
Fazzari, S. M., And B. C. Petersen (1993): "Working Capital and Fixed Investment: New Evidence on Financing Constraints," The RAND Journal of Economics, 24(3), 328-342.

Friedman, B. M., And K. N. Kuttner (1991): "Why Does the Paper-Bill Spread Predict Real Economic Activity?," Working paper, NBER.

Gaspar, J.-M., And M. Massa (2006): "Idiosyncratic Volatility and Product Market Competition," Journal of Business, 79(6), 3125-3152.

Gertler, M., and S. Gilchrist (1994): "Monetary Policy, Business Cycles, and the Behavior of Small Manufacturing Firms," Quarterly Journal of Economics, 109(2), 309-340.

Gilchrist, S., and C. P. Himmelerg (1995): "Evidence on the role of cash flow for investment," Journal of Monetary Economics, 36, 541-572.

Gomes, J. A. F., L. Kogan, and M. Yogo (2009): "Durability of Output and Expected Stock Returns," Journal of Political Economy, 117(5), 941-986.

Gomes, J. F., A. Yaron, and L. Zhang (2006): "Asset Pricing Implications of Firms' Financing Constraints," Review of Financial Studies, 19(4), 1321-1356.

Hall, R. E. (1986): "Market Structure and Macroeconomic Fluctuations," Brookings Papers on Economic Activity, 1986(2), 285-338.

Hamilton, J. D., And D. H. Kim (2002): "A Reexamination of the Predictability of Economic Activity Using the Yield Spread," Journal of Money, Credit and Banking, 34(2), 340-360.

Haskel, J., C. Martin, and I. Small (1995): "Price, Marginal Cost and the Business Cycle," Oxford Bulletin of Economics and Statistics, 57(1), 25-41.

Hoberg, G., And G. Phillips (2010): "Real and Financial Industry Booms and Busts," Journal of Finance, 65(1), 45-86.

Hou, K., And D. T. Robinson (2006): "Industry Concentration and Average Stock Returns," Journal of Finance, 61(4), 1927-1956.

Hubbard, R. G. (1998): "Capital-Market Imperfections and Investment," Journal of Economic Literature, 36, 193-225.

Kaplan, S. N., And L. Zingales (1997): "Do investment-cash flow sensitivities provide useful measures of financing constraints?," Quarterly Journal of Economics, 112, 169-216.

Kovenock, D., and G. M. Phillips (1997): "Capital Structure and Product Market Behaviour: An Examination of Plant Exit and Investment Decisions," The Review of Financial Studies, 10(3), 767-803.

Lamont, O., C. Polk, and J. SaÁ-Requejo (2001): "Financial Constraints and Stock Returns," Review of Financial Studies, 14(2), 529-554.

Livdan, D., H. Sapriza, and L. Zhang (2009): "Financially Constrained Stock Returns," Journal of Finance, 64(4), 1827-1862. 
Martin, S. (1993): Advanced industrial economics. Blackwell.

Moyen, N. (2004): "Investment-Cash Flow Sensitivities: Constrained versus Unconstrained Firms," Journal of Finance, 59(5), 2061-2092.

Oliveira Martins, J., and S. Scarpetta (2002): "Estimation of the cyclical behaviour of mark-ups: A technical note," OECD Economic Studies, 34, 173-188.

Peress, J. (2010): "Product Market Competition, Insider Trading, and Stock Market Efficiency," Journal of Finance, 65(1), 1-44.

Povel, P., And M. Raith (2004): "Financial constraints and product market competition: ex ante vs. ex post incentives," International Journal of Industrial Organization, 22, 917-942.

Rotemberg, J. J., and G. Saloner (1986): "A Supergame-Theoretic Model of Price Wars during Booms," American Economic Review, 76(3), 390-407.

Rotemberg, J. J., And M. Woodford (1991): "Markups and the Business Cycle," NBER Macroeconomics Annual, 6, 63-129.

Sharpe, S. A. (1994): "Financial Market Imperfections, Firm Leverage, and the Cyclicality of Employment," American Economic Review, 84(4), 1060-1074.

Whited, T. M., and G. Wu (2006): "Financial Constraints Risk," Review of Financial Studies, 19(2), 531-559. 
Table 1: Description of the cross section of the data on U.S. companies excluding financials and utilities.

\begin{tabular}{|c|c|c|}
\hline & \# of observations & $\%$ \\
\hline 1977 & 1350 & 1.72 \\
\hline 1978 & 1400 & 1.78 \\
\hline 1979 & 1392 & 1.77 \\
\hline 1980 & 1420 & 1.81 \\
\hline 1981 & 1486 & 1.89 \\
\hline 1982 & 1570 & 2.00 \\
\hline 1983 & 1695 & 2.16 \\
\hline 1984 & 1752 & 2.23 \\
\hline 1985 & 2019 & 2.57 \\
\hline 1986 & 2107 & 2.68 \\
\hline 1987 & 2116 & 2.69 \\
\hline 1988 & 2165 & 2.76 \\
\hline 1989 & 2244 & 2.86 \\
\hline 1990 & 2240 & 2.85 \\
\hline 1991 & 2277 & 2.90 \\
\hline 1992 & 2336 & 2.97 \\
\hline 1993 & 2504 & 3.19 \\
\hline 1994 & 2725 & 3.47 \\
\hline 1995 & 2970 & 3.78 \\
\hline 1996 & 3142 & 4.00 \\
\hline 1997 & 3222 & 4.10 \\
\hline 1998 & 3362 & 4.28 \\
\hline 1999 & 3273 & 4.17 \\
\hline 2000 & 3112 & 3.96 \\
\hline 2001 & 3009 & 3.83 \\
\hline 2002 & 3042 & 3.87 \\
\hline 2003 & 2903 & 3.70 \\
\hline 2004 & 2804 & 3.57 \\
\hline 2005 & 2693 & 3.43 \\
\hline 2006 & 2681 & 3.41 \\
\hline 2007 & 2586 & 3.29 \\
\hline 2008 & 2512 & 3.20 \\
\hline 2009 & 2428 & 3.09 \\
\hline Observations & 78537 & \\
\hline
\end{tabular}


Table 2: Descriptive statistics.

We present descriptive statistics for our sample of U.S. companies, excluding financial companies and utilities. Market equity is the market value of common equity at the end of the fiscal year adjusted by the CPI, Assets is total book assets adjusted by the CPI, ROA is earnings divided by total assets, ROE is earnings available to common shareholders divided by book equity, M/B assets is the market to book ratio measured at fiscal year end, debt/assets is total debt to total assets, real sales growth is sales growth adjusted by the CPI, $\mathrm{P} / \mathrm{O}$ ratio is cash common dividends plus stock repurchases divided by earnings, Capex/Assets is capital expenditures divided by total assets. Variables in levels are in constant 1994 dollar million.

\begin{tabular}{lccccc}
\hline & & & & & \\
& Mean & S.D. & p25 & p50 & p75 \\
\hline Market equity & 1827.7 & 9978.9 & 48.0 & 173.5 & 730.7 \\
Assets & 1805.7 & 10733.6 & 65.4 & 201.9 & 756.9 \\
ROA & 0.0335 & 0.1422 & 0.0178 & 0.0672 & 0.1031 \\
ROE & -0.0003 & 0.3432 & -0.0029 & 0.0840 & 0.1452 \\
M/B assets & 1.6520 & 1.1593 & 0.9878 & 1.2777 & 1.8569 \\
Debt/Assets & 0.2160 & 0.1800 & 0.0502 & 0.1966 & 0.3357 \\
Real sales growth & 0.0981 & 0.3371 & -0.0473 & 0.0484 & 0.1690 \\
P/O ratio & 0.6623 & 1.3811 & 0.0000 & 0.1150 & 0.4677 \\
Capex/Assets & 0.0655 & 0.0636 & 0.0237 & 0.0467 & 0.0843 \\
\hline Observations & 78536 & & & \\
\hline
\end{tabular}

Table 3: Financing constraints and the level of industry concentration.

Percentage of firms deemed as financially constrained in industries with low, medium and high concentration (measured by the fitted Herfindahl-Hirschman index). We use five proxies for financing constraints: the Whited and Wu index, the payout ratio, size measured by total assets, and the presence of a long-term (short-term) issuer rating. We calculate the aggregate proportion of constrained firms in industries with with low (bottom 30\%), medium, and high (top 30\%) concentration. Fitted HHI data are from the Hoberg and Phillips Data Library.

\begin{tabular}{lccc}
\hline & \multicolumn{3}{c}{ Industry } \\
\cline { 2 - 4 } & Low & Medium & High \\
\hline WW, \%firms constrained & 37.4 & 31.8 & 19.7 \\
P/O, \%firms constrained & 50.4 & 47.6 & 34.7 \\
Size, \%firms constrained & 37.7 & 31.4 & 20.4 \\
LT rating, \%firms constrained & 66.7 & 65.1 & 59.4 \\
ST rating, \%firms constrained & 77.6 & 78.4 & 78.8 \\
\hline Observations & 28048 & 35812 & 26692 \\
\hline
\end{tabular}


Table 4: US industries with low concentration and high/low dispersion of firm Lerner indexes as of 2005 .

We present the standard deviations of individual firms' Lerner indexes within 3-digit SIC industries as of 2005. We present industries with a fitted HHI below 500, at the high and low end of the distribution of Lerner standard deviations in that year. Standard deviations of Lerner indexes are calculated on our sample of Compustat US firms satisfying our data requirements. Fitted HHI data are from the Hoberg and Phillips Data Library.

\begin{tabular}{|c|c|c|c|}
\hline Industry name & SIC3 & Fitted HHI & $\sigma($ Lerner $)$ \\
\hline \multicolumn{4}{|c|}{ Panel A: High dispersion of firm Lerner indexes } \\
\hline Gold \& silver ores (mining) & 104 & 436 & 0.175 \\
\hline Crude petrol. \& Nat. Gas (extraction) & 131 & 399 & 0.240 \\
\hline Drugs & 283 & 450 & 0.141 \\
\hline Deep sea foreign trans. of freight & 441 & 500 & 0.146 \\
\hline Tel. communication & 481 & 499 & 0.169 \\
\hline Cable \& other pay TV services & 484 & 473 & 0.159 \\
\hline Advertising & 731 & 495 & 0.133 \\
\hline Misc. equipment rental \& leasing & 735 & 388 & 0.142 \\
\hline Commercial sports & 794 & 481 & 0.187 \\
\hline \multicolumn{4}{|c|}{ Panel B: Low dispersion of firm Lerner indexes } \\
\hline Operative builders & 153 & 355 & 0.044 \\
\hline Womens', Misses', and Juniors' Outerwear & 233 & 423 & 0.069 \\
\hline Newspapers & 271 & 491 & 0.052 \\
\hline Misc. chemical products & 289 & 458 & 0.049 \\
\hline Misc. plastics products & 308 & 444 & 0.049 \\
\hline Blast furnace \& basic steel products & 331 & 481 & 0.066 \\
\hline General ind. machinery & 356 & 423 & 0.064 \\
\hline Machinery, equipment \& supplies (wholesale trade) & 508 & 385 & 0.062 \\
\hline Non-store retailers & 596 & 395 & 0.053 \\
\hline
\end{tabular}


Table 5: The impact of product market competition on the business cycle sensitivity of firm profitability.

We regress $\mathrm{ROA}_{t}$ on four macro variables, a lagged measure of product market competition (PMC), their interactions, a set of lagged firm-level variables, a linear trend and a constant. Column (2) uses PMC = (1 - HHI), based on the fitted Herfindahl-Hirschman index by Hoberg and Phillips (2010). Column (3) is based on the same definition of PMC, but uses only dummies for high and low values of PMC. Column (4) uses a dummy for high and low relative market power (Lerner index of the firm minus its SIC3 sector average). GDPGR is the annual real U.S. GDP growth, DCPSPR is the change of the average CP spread, DBSPR is the change of the average bond spread, DTSPR is the change of the average term spread. The macro variables were orthogonalized and standardized. PMC is standardized. The firm controls are Capex/Assets, PPE/Assets, a dividend payer dummy, (Dividends+Repurchases)/Book equity, and the M/B of assets. Lox $\left(\mathrm{Hi}_{\mathrm{X}}\right)$ is an indicator variable for observations in the bottom (top) $30 \%$ in the previous year's cross-section of the measure X. We use all Compustat CCM firms satisfying our data requirements (excl. finance and utilities). The estimation period is from 1977 to 2009. Estimated using a firm fixed effect estimator with firm-clustered standard errors. We present selected coefficients. Reported $\mathrm{R}^{2}$ exclude the variability explained by the fixed effects.

\begin{tabular}{|c|c|c|c|c|}
\hline & $\begin{array}{c}(1) \\
\text { Baseline }\end{array}$ & $\begin{array}{c}(2) \\
\text { PMC level }\end{array}$ & $\begin{array}{c}(3) \\
\mathrm{X}=\mathrm{PMC}\end{array}$ & $\begin{array}{c}(4) \\
\mathrm{X}=\text { Lerner index }\end{array}$ \\
\hline GDPGR & $\begin{array}{l}0.0036^{* * *} \\
(7.99)\end{array}$ & $\begin{array}{l}0.0045^{* * *} \\
(8.48)\end{array}$ & $\begin{array}{l}0.0048^{* * *} \\
(5.60)\end{array}$ & $\begin{array}{l}0.0052^{* * *} \\
(8.24)\end{array}$ \\
\hline DCPSPR & $\begin{array}{l}0.0007 \\
(1.88)\end{array}$ & $\begin{array}{l}0.0011^{* *} \\
(2.68)\end{array}$ & $\begin{array}{l}0.0001 \\
(0.10)\end{array}$ & $\begin{array}{l}-0.0003 \\
(-0.58)\end{array}$ \\
\hline DBSPR & $\begin{array}{l}-0.0037^{* * *} \\
(-9.41)\end{array}$ & $\begin{array}{l}-0.0039^{* * *} \\
(-9.25)\end{array}$ & $\begin{array}{l}-0.0055^{* * *} \\
(-7.43)\end{array}$ & $\begin{array}{l}-0.0028^{* * *} \\
(-4.95)\end{array}$ \\
\hline DTSPR & $\begin{array}{l}-0.0061^{* * *} \\
(-17.14)\end{array}$ & $\begin{array}{l}-0.0063^{* * *} \\
(-16.45)\end{array}$ & $\begin{array}{l}-0.0073^{* * *} \\
(-10.77)\end{array}$ & $\begin{array}{l}-0.0065^{* * *} \\
(-13.48)\end{array}$ \\
\hline GDPGR $\times$ PMC & & $\begin{array}{l}0.0015^{* * *} \\
(3.93)\end{array}$ & & \\
\hline $\mathrm{DCPSPR} \times \mathrm{PMC}$ & & $\begin{array}{l}0.0005 \\
(1.68)\end{array}$ & & \\
\hline $\mathrm{DBPSPR} \times \mathrm{PMC}$ & & $\begin{array}{l}-0.0024^{* * *} \\
(-7.34)\end{array}$ & & \\
\hline DTPSPR $\times$ PMC & & $\begin{array}{l}-0.0024^{* * *} \\
(-8.01)\end{array}$ & & \\
\hline GDPGR $\times$ Lox & & & $\begin{array}{l}-0.0029^{* *} \\
(-2.66)\end{array}$ & $\begin{array}{l}-0.0012 \\
(-0.84)\end{array}$ \\
\hline $\mathrm{GDPGR} \times \mathrm{Hi}_{\mathrm{X}}$ & & & $\begin{array}{l}0.0001 \\
(0.10)\end{array}$ & $\begin{array}{l}-0.0032^{* * *} \\
(-3.54)\end{array}$ \\
\hline $\mathrm{DCPSPR} \times$ Lox & & & $\begin{array}{l}0.0008 \\
(0.98)\end{array}$ & $\begin{array}{l}0.0028^{* *} \\
(2.65)\end{array}$ \\
\hline $\mathrm{DCPSPR} \times \mathrm{Hi}_{\mathrm{X}}$ & & & $\begin{array}{l}0.0024^{*} \\
(2.34)\end{array}$ & $\begin{array}{l}0.0017^{*} \\
(2.24)\end{array}$ \\
\hline DBSPR $\times$ Lox & & & $\begin{array}{l}0.0053^{* * *} \\
(5.66)\end{array}$ & $\begin{array}{l}-0.0045^{* * *} \\
(-3.62)\end{array}$ \\
\hline $\mathrm{DBSPR} \times \mathrm{Hi}_{\mathrm{X}}$ & & & $\begin{array}{l}-0.0003 \\
(-0.30)\end{array}$ & $\begin{array}{l}0.0002 \\
(0.28)\end{array}$ \\
\hline $\mathrm{DTSPR} \times \operatorname{Lo}_{\mathrm{X}}$ & & & $\begin{array}{l}0.0041^{* * *} \\
(4.79)\end{array}$ & $\begin{array}{l}-0.0014 \\
(-1.21)\end{array}$ \\
\hline $\mathrm{DTSPR} \times \mathrm{Hi}_{\mathrm{X}}$ & & & $\begin{array}{l}-0.0009 \\
(-0.84)\end{array}$ & $\begin{array}{l}0.0016^{*} \\
(2.21)\end{array}$ \\
\hline Trend and firm controls & Yes & Yes & Yes & Yes \\
\hline Observations & 78537 & 70722 & 70722 & 71317 \\
\hline Adjusted $R^{2}$ & 0.070 & 0.070 & 0.070 & 0.084 \\
\hline
\end{tabular}


Table 6: The impact of financing constraints on the business cycle sensitivity of firm profitability.

We regress $\mathrm{ROA}_{t}$ on four macro variables, a measure of firm financing constraints, their interactions, a set of lagged firm-level variables, a linear trend and a constant. In columns (2)-(6) we interact the macro variables with a lagged indicator of high or low financing constraints (FC). Column (2) shows results based on the Whited and Wu index, (3) uses the payout ratio, (4) uses size, (5) and (6) use the presence of a long-term (short-term) issuer rating. GDPGR is the annual real U.S. GDP growth, DCPSPR is the change of the average CP spread, DBSPR is the change of the average bond spread, DTSPR is the change of the average term spread. The macro variables were decorrelated and standardized. The firm controls are Capex/Assets, PPE/Assets, a dividend payer dummy, (Dividends+Repurchases)/Book equity, and the M/B of assets. In columns (2) to (4) $\mathrm{Lo}_{\mathrm{FC}}\left(\mathrm{Hi}_{\mathrm{FC}}\right)$ is an indicator variable for the $30 \%$ least (most) likely constrained firms in the previous year's cross-section. In columns (5) and (6) $\mathrm{LoFC}_{\mathrm{FC}}$ is an indicator for firms having a valid non-default rating and positive debt in the previous year. We use all Compustat CCM firms satisfying our data requirements (excl. finance and utilities). The estimation period is from 1977 to 2009 except where ratings data are used (available 1985 onwards). Results obtained using the firm fixed effect estimator with firm-clustered standard errors. We present selected coefficients. Reported $\mathrm{R}^{2}$ exclude the variability explained by the fixed effects.

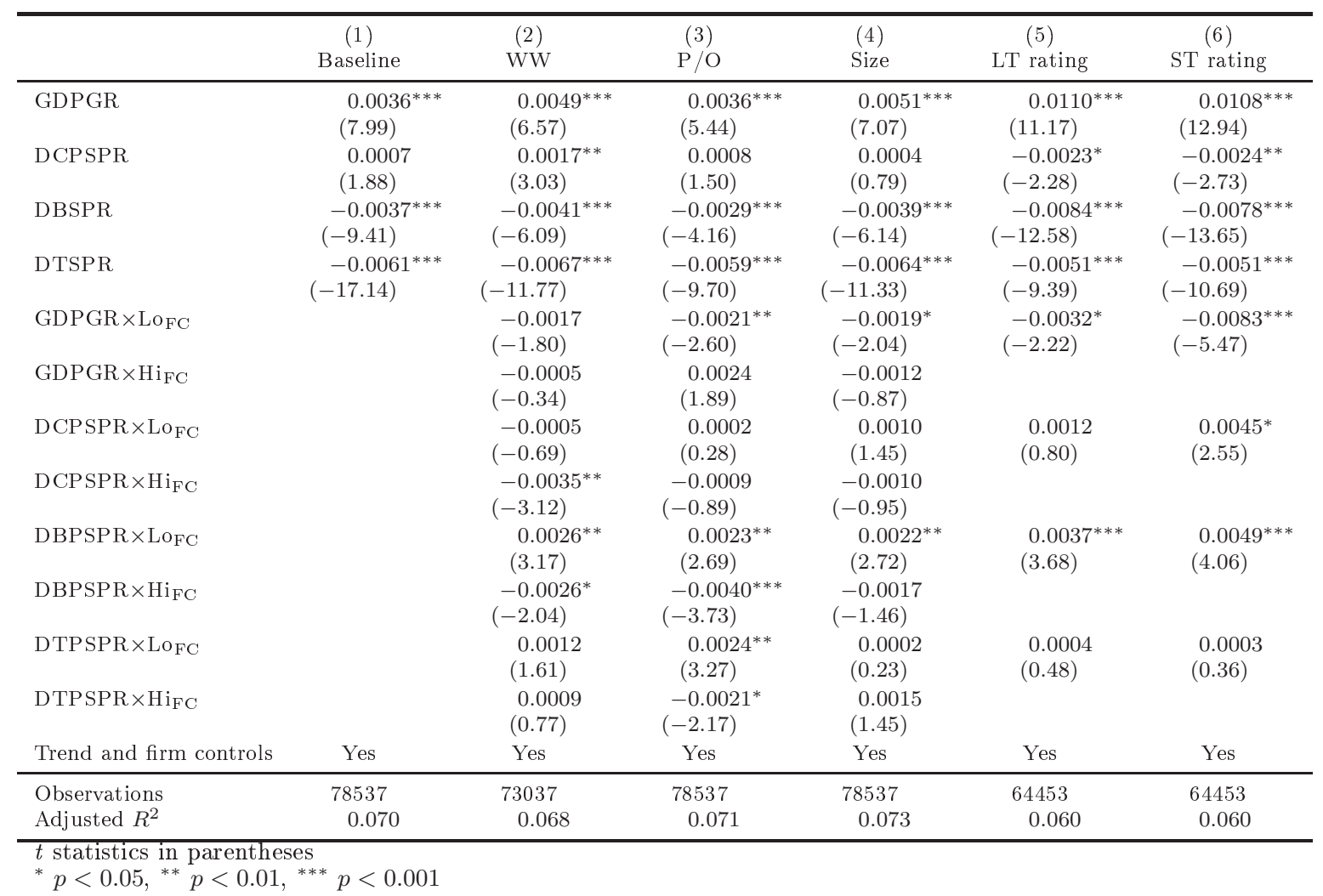


Table 7: The joint effect of financing constraints and product market competition.

We regress $\mathrm{ROA}_{t}$ on four macro variables, measures of financing constraints, a measure of product market competition, their interactions, a set of lagged firm-level variables, a linear trend and a constant. Each column uses a different measure of financing constraints. PMC is the lagged value of $(1-\mathrm{HHI})$, based on the fitted Herfindahl-Hirschman index by Hoberg and Phillips (2010). The firm controls and macro variables are as in previous tables. We use all Compustat CCM firms satisfying our data requirements (excl. finance and utilities). The estimation period is from 1977 to 2009 except where ratings data are used (available 1985 onwards). Results obtained using the firm fixed effect estimator with firm-clustered standard errors. We present selected coefficients. Reported $R^{2}$ exclude the variability explained by the fixed effects.

\begin{tabular}{|c|c|c|c|c|c|}
\hline & $\begin{array}{c}(1) \\
\text { WW }\end{array}$ & $\begin{array}{c}(2) \\
\mathrm{P} / \mathrm{O}\end{array}$ & $\begin{array}{c}(3) \\
\text { Size }\end{array}$ & $\begin{array}{l}(4) \\
\mathrm{LT} \text { rating }\end{array}$ & ST rating \\
\hline GDPGR & $\begin{array}{l}0.0053^{* * *} \\
(6.57)\end{array}$ & $\begin{array}{l}0.0045^{* * *} \\
(5.74)\end{array}$ & $\begin{array}{l}0.0060^{* * *} \\
(7.43)\end{array}$ & $\begin{array}{l}0.0112^{\text {*** }} \\
(10.94)\end{array}$ & $\begin{array}{l}0.0113^{* * *} \\
(12.83)\end{array}$ \\
\hline DCPSPR & $\begin{array}{l}0.0021^{* * * *} \\
(3.35)\end{array}$ & $\begin{array}{l}0.0012^{*} \\
(2.04)\end{array}$ & $\begin{array}{l}0.0011 \\
(1.84)\end{array}$ & $\begin{array}{l}-0.0016 \\
(-1.46)\end{array}$ & $\begin{array}{l}-0.0015 \\
(-1.65)\end{array}$ \\
\hline DBSPR & $\begin{array}{l}-0.0038^{* * *} \\
(-5.48)\end{array}$ & $\begin{array}{l}-0.0032^{* * *} \\
(-4.24)\end{array}$ & $\begin{array}{l}-0.0039^{* * *} \\
(-5.85)\end{array}$ & $\begin{array}{l}-0.0081^{* * *} \\
(-11.75)\end{array}$ & $\begin{array}{l}-0.0077^{* * *} \\
(-12.80)\end{array}$ \\
\hline DTSPR & $\begin{array}{l}-0.0069^{* * *} \\
(-11.66)\end{array}$ & $\begin{array}{l}-0.0061^{* * *} \\
(-9.11)\end{array}$ & $\begin{array}{l}-0.0067^{* * *} \\
(-11.19)\end{array}$ & $\begin{array}{l}-0.0052^{* * *} \\
(-9.15)\end{array}$ & $\begin{array}{l}-0.0052^{* * *} \\
(-10.50)\end{array}$ \\
\hline $\mathrm{GDPGR} \times \mathrm{PMC}$ & $\begin{array}{l}0.0007 \\
(0.96)\end{array}$ & $\begin{array}{l}0.0014^{*} \\
(2.55)\end{array}$ & $\begin{array}{l}0.0016^{*} \\
(2.34)\end{array}$ & $\begin{array}{l}0.0022^{* *} \\
(2.66)\end{array}$ & $\begin{array}{l}0.0021^{* *} \\
(3.14)\end{array}$ \\
\hline $\mathrm{DCPSPR} \times \mathrm{PMC}$ & $\begin{array}{l}0.0009 \\
(1.49)\end{array}$ & $\begin{array}{l}0.0010^{*} \\
(2.32)\end{array}$ & $\begin{array}{l}0.0010 \\
(1.77)\end{array}$ & $\begin{array}{l}0.0015 \\
(1.58)\end{array}$ & $\begin{array}{l}0.0012 \\
(1.51)\end{array}$ \\
\hline $\mathrm{DBSPR} \times \mathrm{PMC}$ & $\begin{array}{l}-0.0027^{* * *} \\
(-4.38)\end{array}$ & $\begin{array}{l}-0.0023^{* * *} \\
(-4.13)\end{array}$ & $\begin{array}{l}-0.0026^{* * *} \\
(-4.54)\end{array}$ & $\begin{array}{l}-0.0027^{* * *} \\
(-4.94)\end{array}$ & $\begin{array}{l}-0.0023^{* * *} \\
(-5.28)\end{array}$ \\
\hline $\mathrm{DTSPR} \times \mathrm{PMC}$ & $\begin{array}{l}-0.0025^{* * *} \\
(-4.53)\end{array}$ & $\begin{array}{l}-0.0017^{* * *} \\
(-3.61)\end{array}$ & $\begin{array}{l}-0.0032^{* * *} \\
(-6.36)\end{array}$ & $\begin{array}{l}-0.0031^{* * *} \\
(-5.85)\end{array}$ & $\begin{array}{l}-0.0027^{* * *} \\
(-6.24)\end{array}$ \\
\hline $\mathrm{GDPGR} \times \mathrm{Lo}_{\mathrm{FC}}$ & $\begin{array}{l}-0.0009 \\
(-0.88)\end{array}$ & $\begin{array}{l}-0.0029^{* *} \\
(-2.96)\end{array}$ & $\begin{array}{l}-0.0018 \\
(-1.66)\end{array}$ & $\begin{array}{l}-0.0019 \\
(-1.24)\end{array}$ & $\begin{array}{l}-0.0081^{* * *} \\
(-4.67)\end{array}$ \\
\hline $\mathrm{GDPGR} \times \mathrm{Hi}_{\mathrm{FC}}$ & $\begin{array}{l}-0.0006 \\
(-0.43)\end{array}$ & $\begin{array}{l}0.0020 \\
(1.45)\end{array}$ & $\begin{array}{l}-0.0021 \\
(-1.44)\end{array}$ & & \\
\hline $\mathrm{DCPSPR} \times \mathrm{LoFC}_{\mathrm{FC}}$ & $\begin{array}{l}-0.0004 \\
(-0.46)\end{array}$ & $\begin{array}{l}-0.0004 \\
(-0.46)\end{array}$ & $\begin{array}{l}0.0007 \\
(0.80)\end{array}$ & $\begin{array}{l}0.0009 \\
(0.55)\end{array}$ & $\begin{array}{l}0.0029 \\
(1.37)\end{array}$ \\
\hline $\mathrm{DCPSPR} \times \mathrm{Hi}_{\mathrm{FC}}$ & $\begin{array}{l}-0.0037^{* *} \\
(-3.12)\end{array}$ & $\begin{array}{l}-0.0007 \\
(-0.58)\end{array}$ & $\begin{array}{l}-0.0015 \\
(-1.29)\end{array}$ & & \\
\hline $\mathrm{DBSPR} \times \mathrm{Lo}_{\mathrm{FC}}$ & $\begin{array}{l}0.0021^{*} \\
(2.36)\end{array}$ & $\begin{array}{l}0.0025^{* *} \\
(2.67)\end{array}$ & $\begin{array}{l}0.0020^{*} \\
(2.22)\end{array}$ & $\begin{array}{l}0.0034^{* *} \\
(3.10)\end{array}$ & $\begin{array}{l}0.0045^{* *} \\
(3.15)\end{array}$ \\
\hline $\mathrm{DBSPR} \times \mathrm{Hi}_{\mathrm{FC}}$ & $\begin{array}{l}-0.0018 \\
(-1.40)\end{array}$ & $\begin{array}{l}-0.0033^{* *} \\
(-2.91)\end{array}$ & $\begin{array}{l}-0.0012 \\
(-0.96)\end{array}$ & & \\
\hline $\mathrm{DTSPR} \times \mathrm{Lo}_{\mathrm{FC}}$ & $\begin{array}{l}0.0005 \\
(0.69)\end{array}$ & $\begin{array}{l}0.0022^{* *} \\
(2.74)\end{array}$ & $\begin{array}{l}-0.0001 \\
(-0.11)\end{array}$ & $\begin{array}{l}0.0002 \\
(0.18)\end{array}$ & $\begin{array}{l}0.0002 \\
(0.17)\end{array}$ \\
\hline $\mathrm{DTSPR} \times \mathrm{Hi}_{\mathrm{FC}}$ & $\begin{array}{l}0.0018 \\
(1.60)\end{array}$ & $\begin{array}{l}-0.0015 \\
(-1.45)\end{array}$ & $\begin{array}{l}0.0024^{*} \\
(2.13)\end{array}$ & & \\
\hline $\mathrm{GDPGR} \times \mathrm{Lo}_{\mathrm{FC}} \times \mathrm{PMC}$ & $\begin{array}{ll} & 0.0005 \\
(0.58)\end{array}$ & $\begin{array}{l}-0.0022^{* *} \\
(-3.11)\end{array}$ & $\begin{array}{l}-0.0007 \\
(-0.86)\end{array}$ & $\begin{array}{l}-0.0005 \\
(-0.44)\end{array}$ & $\begin{array}{l}-0.0020^{*} \\
(-2.08)\end{array}$ \\
\hline $\mathrm{GDPGR} \times \mathrm{Hi}_{\mathrm{FC}} \times \mathrm{PMC}$ & $\begin{array}{ll} & 0.0038^{* *} \\
& (2.64)\end{array}$ & $\begin{array}{l}0.0026^{*} \\
(2.40)\end{array}$ & $\begin{array}{l}0.0013 \\
(0.85)\end{array}$ & & \\
\hline $\mathrm{DCPSPR} \times \mathrm{Lo}_{\mathrm{FC}} \times \mathrm{PM}$ & $\begin{array}{l}\mathrm{IC}-0.0002 \\
(-0.30)\end{array}$ & $\begin{array}{l}-0.0015^{*} \\
(-2.56)\end{array}$ & $\begin{array}{l}-0.0004 \\
(-0.66)\end{array}$ & $\begin{array}{l}-0.0022 \\
(-1.75)\end{array}$ & $\begin{array}{l}-0.0023 \\
(-1.73)\end{array}$ \\
\hline $\mathrm{DCPSPR} \times \mathrm{Hi}_{\mathrm{FC}} \times \mathrm{PMC}$ & $\begin{array}{l}{[\mathrm{C}-0.0010} \\
(-0.71)\end{array}$ & $\begin{array}{l}0.0003 \\
(0.26)\end{array}$ & $\begin{array}{l}-0.0004 \\
(-0.29)\end{array}$ & & \\
\hline $\mathrm{DBSPR} \times \mathrm{LO}_{\mathrm{FC}} \times \mathrm{PMC}$ & $\begin{array}{l}0.0014 \\
(1.87)\end{array}$ & $\begin{array}{l}0.0016^{*} \\
(2.38)\end{array}$ & $\begin{array}{l}0.0015^{*} \\
(2.11)\end{array}$ & $\begin{array}{l}0.0020^{* *} \\
(2.72)\end{array}$ & $\begin{array}{l}0.0024^{* *} \\
(2.97)\end{array}$ \\
\hline $\mathrm{DBSPR} \times \mathrm{Hi}_{\mathrm{FC}} \times \mathrm{PMC}$ & $\begin{array}{l}-0.0033^{*} \\
(-2.38)\end{array}$ & $\begin{array}{l}-0.0014 \\
(-1.53)\end{array}$ & $\begin{array}{l}-0.0021 \\
(-1.68)\end{array}$ & & \\
\hline $\mathrm{DTSPR} \times \mathrm{Lo}_{\mathrm{FC}} \times \mathrm{PMC}$ & $\begin{array}{l}-0.0005 \\
(-0.71)\end{array}$ & $\begin{array}{l}0.0006 \\
(0.95)\end{array}$ & $\begin{array}{l}0.0010 \\
(1.67)\end{array}$ & $\begin{array}{l}0.0022^{* *} \\
(3.22)\end{array}$ & $\begin{array}{l}0.0023^{* * *} \\
(3.83)\end{array}$ \\
\hline $\mathrm{DTSPR} \times \mathrm{Hi}_{\mathrm{FC}} \times \mathrm{PMC}$ & $\begin{array}{l}-0.0001 \\
(-0.11)\end{array}$ & $\begin{array}{l}-0.0021^{*} \\
(-2.45)\end{array}$ & $\begin{array}{l}0.0013 \\
(1.08)\end{array}$ & & \\
\hline Trend \& controls & Yes & Yes & Yes & Yes & Yes \\
\hline $\begin{array}{l}\text { Observations } \\
\text { Adjusted } R^{2}\end{array}$ & $\begin{array}{r}67385 \\
0.070\end{array}$ & $\begin{array}{l}70722 \\
0.072\end{array}$ & $\begin{array}{l}70722 \\
0.073\end{array}$ & $\begin{array}{r}58176 \\
0.061\end{array}$ & $\begin{array}{r}58176 \\
0.061\end{array}$ \\
\hline
\end{tabular}


Table 8: Business cycle sensitivity of fixed investment.

We regress annual firm investment rates on the real GDP growth, a measure of product market competition (PMC), their interaction, and a set of lagged controls (coefficients not reported). We split the sample based on the level of financing constraints using five proxies. Investment is defined as capital expenditures divided by net property, plant and equipment. Our control variables include lagged values of the market-to-book ratio of assets, cash flow to assets measured as operating income before depreciation divided by total assets, the log of total assets, the ratio of physical capital (PPE) to total assets, the dividend payer dummy, the growth rate of sales of the three-digit SIC industry, and a constant. PMC is the lagged value of (1- HHI), based on the SIC3 fitted Herfindahl-Hirschman index from the Hoberg and Phillips data library. PMC and GDP growth are standardized. We use all Compustat CCM firms satisfying our data requirements and with PPE/assets above $5 \%$. The estimation period is from 1977 to 2009 except where ratings data are used (available 1985 onwards). Results obtained using a firm fixed effect estimator with firm-clustered standard errors. Reported $\mathrm{R}^{2}$ exclude the variability explained by the fixed effects.

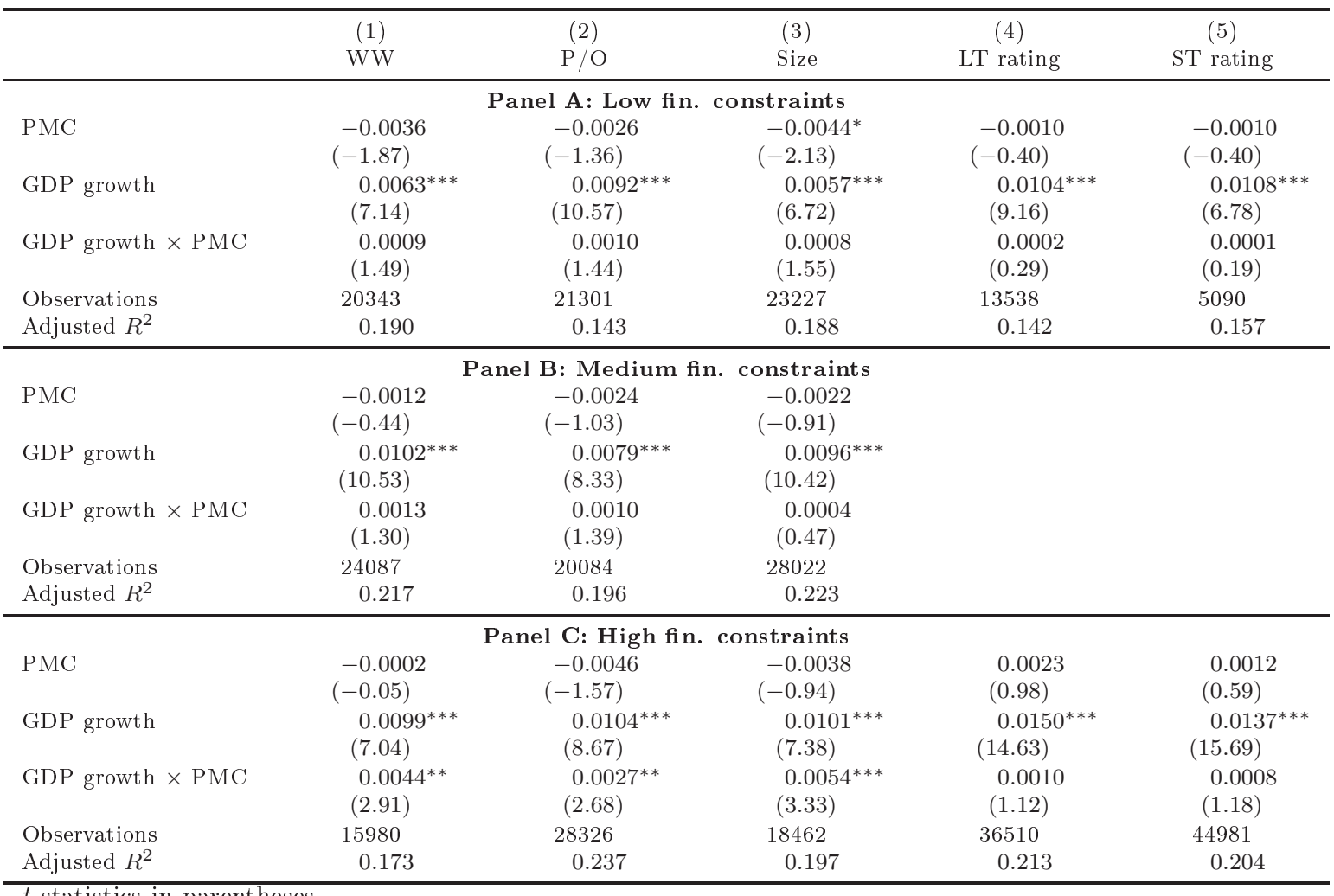

$t$ statistics in parentheses

${ }^{*} p<0.05,{ }^{* *} p<0.01,{ }^{* * *} p<0.001$ 
Table 9: Business cycle sensitivity of net working capital.

We regress annual firm investment in net working capital on the real GDP growth, a measure of product market competition (PMC), their interaction, and a set of lagged controls (coefficients not reported). We split the sample based on the level of financing constraints using five proxies. NWC is current assets less cash\&STI less current liabilities. NWC investment is the change of NWC divided by net property, plant and equipment. Our control variables include lagged values of the market-to-book ratio of assets, cash flow to assets measured as operating income before depreciation divided by total assets, the log of total assets, the ratio of physical capital (PPE) to total assets, the dividend payer dummy, the growth rate of sales of the three-digit SIC industry, and a constant. PMC is the lagged value of $(1-\mathrm{HHI})$, based on the SIC3 fitted Herfindahl-Hirschman index from the Hoberg and Phillips data library. PMC and GDP growth are standardized. We use all Compustat CCM firms satisfying our data requirements and with PPE/assets above $5 \%$. The estimation period is from 1977 to 2009 except where ratings data are used (available 1985 onwards). Results obtained using a firm fixed effect estimator with firm-clustered standard errors. Reported $R^{2}$ exclude the variability explained by the fixed effects.

\begin{tabular}{|c|c|c|c|c|c|}
\hline & $\begin{array}{c}(1) \\
\text { WW }\end{array}$ & $\begin{array}{l}(2) \\
\mathrm{P} / \mathrm{O}\end{array}$ & $\begin{array}{l}(3) \\
\text { Size }\end{array}$ & LT $\stackrel{(4)}{\text { rating }}$ & $\begin{array}{l}(5) \\
\text { ST rating }\end{array}$ \\
\hline \multicolumn{6}{|c|}{ Panel A: Low fin. constraints } \\
\hline $\mathrm{PMC}$ & $\begin{array}{l}-0.0073 \\
(-0.95)\end{array}$ & $\begin{array}{l}-0.0165^{* *} \\
(-2.65)\end{array}$ & $\begin{array}{l}-0.0063 \\
(-1.16)\end{array}$ & $\begin{array}{l}0.0052 \\
(0.71)\end{array}$ & $\begin{array}{l}0.0049 \\
(0.73)\end{array}$ \\
\hline GDP growth & $\begin{array}{l}0.0023 \\
(0.76)\end{array}$ & $\begin{array}{l}0.0211^{* * *} \\
(6.07)\end{array}$ & $\begin{array}{l}0.0077^{*} \\
(2.50)\end{array}$ & $\begin{array}{l}0.0056 \\
(1.12)\end{array}$ & $\begin{array}{l}-0.0107 \\
(-1.77)\end{array}$ \\
\hline GDP growth $\times$ PMC & $\begin{array}{l}-0.0023 \\
(-1.16)\end{array}$ & $\begin{array}{l}-0.0034 \\
(-1.24)\end{array}$ & $\begin{array}{l}0.0005 \\
(0.26)\end{array}$ & $\begin{array}{l}0.0029 \\
(0.99)\end{array}$ & $\begin{array}{l}0.0016 \\
(0.50)\end{array}$ \\
\hline Observations & 19618 & 20706 & 22314 & 12946 & 4851 \\
\hline Adjusted $R^{2}$ & 0.011 & 0.013 & 0.010 & 0.006 & 0.001 \\
\hline \multicolumn{6}{|c|}{ Panel B: Medium fin. constraints } \\
\hline $\mathrm{PMC}$ & $\begin{array}{l}-0.0257^{*} \\
(-2.25)\end{array}$ & $\begin{array}{l}-0.0056 \\
(-0.61)\end{array}$ & $\begin{array}{l}-0.0118 \\
(-1.33)\end{array}$ & & \\
\hline GDP growth & $\begin{array}{l}0.0354^{* * *} \\
(7.98)\end{array}$ & $\begin{array}{l}0.0242^{* * *} \\
(5.35)\end{array}$ & $\begin{array}{l}0.0382^{* * *} \\
(9.43)\end{array}$ & & \\
\hline GDP growth $\times$ PMC & $\begin{array}{l}0.0018 \\
(0.48)\end{array}$ & $\begin{array}{l}0.0025 \\
(0.90)\end{array}$ & $\begin{array}{l}0.0045 \\
(1.33)\end{array}$ & & \\
\hline Observations & 23402 & 19466 & 27226 & & \\
\hline Adjusted $R^{2}$ & 0.032 & 0.022 & 0.024 & & \\
\hline \multicolumn{6}{|c|}{ Panel C: High fin. constraints } \\
\hline PMC & $\begin{array}{l}-0.0170 \\
(-0.87)\end{array}$ & $\begin{array}{l}-0.0248^{*} \\
(-2.01)\end{array}$ & $\begin{array}{l}-0.0381^{*} \\
(-1.98)\end{array}$ & $\begin{array}{l}-0.0139 \\
(-1.33)\end{array}$ & $\begin{array}{l}-0.0100 \\
(-1.23)\end{array}$ \\
\hline GDP growth & $\begin{array}{l}0.0510^{* * *} \\
(6.68)\end{array}$ & $\begin{array}{l}0.0412^{* * *} \\
(6.96)\end{array}$ & $\begin{array}{l}0.0545^{* * *} \\
(8.00)\end{array}$ & $\begin{array}{l}0.0417^{* * *} \\
(7.37)\end{array}$ & $\begin{array}{l}0.0339^{* * *} \\
(7.38)\end{array}$ \\
\hline GDP growth $\times$ PMC & $\begin{array}{l}0.0076 \\
(0.89)\end{array}$ & $\begin{array}{l}0.0103^{*} \\
(2.22)\end{array}$ & $\begin{array}{l}0.0035 \\
(0.43)\end{array}$ & $\begin{array}{l}-0.0008 \\
(-0.17)\end{array}$ & $\begin{array}{l}0.0010 \\
(0.30)\end{array}$ \\
\hline Observations & 15652 & 27459 & 18091 & 35355 & 43468 \\
\hline Adjusted $R^{2}$ & 0.019 & 0.030 & 0.028 & 0.021 & 0.020 \\
\hline
\end{tabular}


Table 10: Business cycle sensitivity of employment.

We regress annual firm employment growth on the real GDP growth, a measure of product market competition (PMC), their interaction, and a set of lagged controls (coefficients not reported). We split the sample based on the level of financing constraints using five proxies. Employment growth is the growth rate of the number of employees. Our control variables include lagged values of the market-to-book ratio of assets, cash flow to assets measured as operating income before depreciation divided by total assets, the log of total assets, the ratio of physical capital (PPE) to total assets, the dividend payer dummy, the growth rate of sales of the three-digit SIC industry, and a constant. PMC is the lagged value of (1 - HHI), based on the SIC3 fitted HerfindahlHirschman index from the Hoberg and Phillips data library. PMC and GDP growth are standardized. We use all Compustat CCM firms satisfying our data requirements and with an asset growth within the $(-50 \%,+100 \%)$ range. The estimation period is from 1977 to 2009 except where ratings data are used (available 1985 onwards). Results obtained using a firm fixed effect estimator with firm-clustered standard errors. Reported $\mathrm{R}^{2}$ exclude the variability explained by the fixed effects.

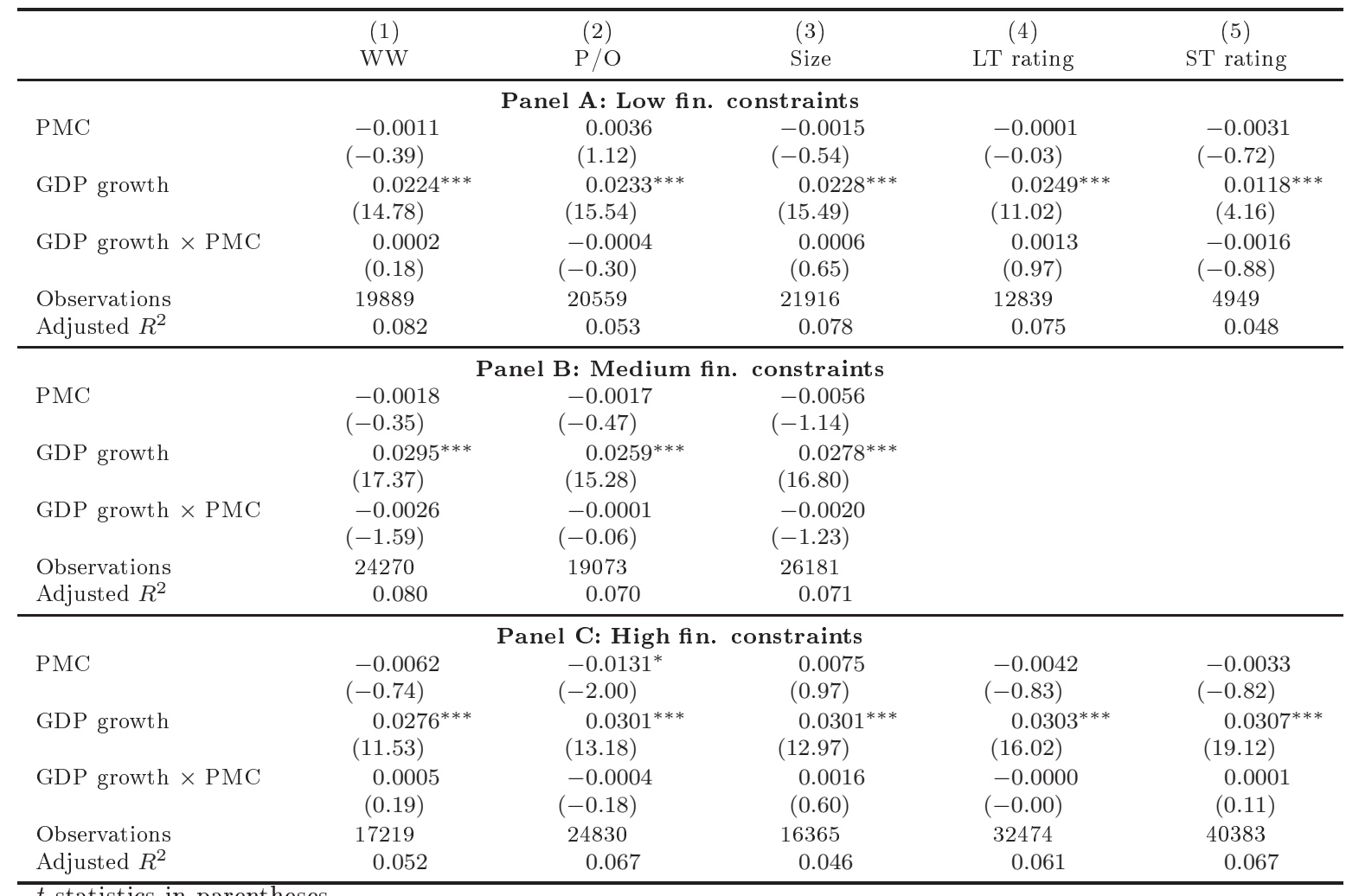

$t$ statistics in parentheses

${ }^{*} p<0.05,{ }^{* *} p<0.01,{ }^{* * *} p<0.001$ 
Table 11: Time-series regressions of double-sorted portfolio returns.

We regress value-weighted monthly excess returns of portfolios on three Fama-French factors and the momentum factor. We merge Compustat fundamentals data with CRSP returns and use all firms that satisfy our fundamentals data requirements and have returns data. We construct independently double-sorted portfolios at the end of June of year $t$, based on year $t-1$ proxies of product market competition and of financing constraints. Low PMC (High PMC) are the bottom (top) three deciles of observations based on the product market competition proxy. Low FC (High FC) are the bottom (top) three deciles of observations based on one of three financing constraints proxies. Panel A uses the WW index, Panel B uses the P/O ratio, and Panel C the size (total assets) as proxy of FC. The explanatory variables are from Kenneth French's webpage: Mkt- $\mathrm{R}_{\mathrm{f}}$ is the market excess return, SMB is the small minus big return, HML is the high minus low B/M return, MOM is the momentum factor return. Regressions are estimated on the period July 1977 to December 2009 , i.e. 390 monthly observations. We present t-statistics using Newey-West standard errors with 4 lags.

\begin{tabular}{|c|c|c|c|c|c|c|c|c|c|}
\hline & \multicolumn{3}{|c|}{ Low PMC } & \multicolumn{3}{|c|}{ Medium PMC } & \multicolumn{3}{|c|}{ High PMC } \\
\hline & Low FC & Med FC & High FC & Low FC & Med FC & High FC & Low FC & Med FC & High FC \\
\hline & \multicolumn{9}{|c|}{ Panel A: WW index } \\
\hline Mkt- $R_{f}$ & $\begin{array}{l}0.913^{* * *} \\
(36.89)\end{array}$ & $\begin{array}{l}1.119^{* * *} \\
(24.66)\end{array}$ & $\begin{array}{l}1.037^{* * *} \\
(22.46)\end{array}$ & $\begin{array}{l}0.950^{* * *} \\
(40.38)\end{array}$ & $\begin{array}{l}1.120^{* * *} \\
(30.11)\end{array}$ & $\begin{array}{l}1.111^{* * * *} \\
(23.68)\end{array}$ & $\begin{array}{l}1.101^{* * *} \\
(31.03)\end{array}$ & $\begin{array}{l}1.121^{* * *} \\
(44.60)\end{array}$ & $\begin{array}{l}1.103^{* * *} \\
(25.18)\end{array}$ \\
\hline SMB & $\begin{array}{l}-0.191^{* * *} \\
(-4.43)\end{array}$ & $\begin{array}{l}0.540^{* * *} \\
(3.67)\end{array}$ & $\begin{array}{l}0.871^{* * *} \\
(6.89)\end{array}$ & $\begin{array}{l}-0.142^{* * *} \\
(-5.28)\end{array}$ & $\begin{array}{l}0.875^{* * *} \\
(14.42)\end{array}$ & $\begin{array}{l}1.368^{* * *} \\
(12.54)\end{array}$ & $\begin{array}{l}-0.009 \\
(-0.13)\end{array}$ & $\begin{array}{c}0.786^{* * *} \\
(15.82)\end{array}$ & $\begin{array}{l}1.182^{* * *} \\
(18.59)\end{array}$ \\
\hline HML & $\begin{array}{l}0.202^{* * *} \\
(4.10)\end{array}$ & $\begin{array}{c}0.146 \\
(1.41)\end{array}$ & $\begin{array}{c}-0.035 \\
(-0.39)\end{array}$ & $\begin{array}{l}-0.260^{* * *} \\
(-8.50)\end{array}$ & $\begin{array}{l}-0.457^{\text {**** }} \\
(-8.32)\end{array}$ & $\begin{array}{l}-0.607^{* * *} \\
(-7.94)\end{array}$ & $\begin{array}{l}-0.393^{* * *} \\
(-6.71)\end{array}$ & $\begin{array}{l}-0.329^{* * *} \\
(-7.07)\end{array}$ & $\begin{array}{l}-0.380^{* * *} \\
(-4.87)\end{array}$ \\
\hline MOM & $\begin{array}{r}0.006 \\
(0.20)\end{array}$ & $\begin{array}{l}-0.020 \\
(-0.40)\end{array}$ & $\begin{array}{c}0.022 \\
(0.40)\end{array}$ & $\begin{array}{l}-0.023 \\
(-0.80)\end{array}$ & $\begin{array}{l}-0.040 \\
(-0.94)\end{array}$ & $\begin{array}{l}-0.024 \\
(-0.34)\end{array}$ & $\begin{array}{l}-0.045 \\
(-1.07)\end{array}$ & $\begin{array}{c}0.019 \\
(0.57)\end{array}$ & $\begin{array}{l}-0.067 \\
(-0.83)\end{array}$ \\
\hline Constant & $\begin{array}{c}0.030 \\
(0.38)\end{array}$ & $\begin{array}{l}-0.129 \\
(-0.95)\end{array}$ & $\begin{array}{l}-0.020 \\
(-0.12)\end{array}$ & $\begin{array}{l}0.155^{*} \\
(1.90)\end{array}$ & $\begin{array}{c}0.119 \\
(0.88)\end{array}$ & $\begin{array}{c}0.010 \\
(0.06)\end{array}$ & $\begin{array}{l}0.257^{* *} \\
(2.06)\end{array}$ & $\begin{array}{c}0.091 \\
(0.86)\end{array}$ & $\begin{array}{l}-0.126 \\
(-0.61)\end{array}$ \\
\hline & \multicolumn{9}{|c|}{ Panel B: $\mathrm{P} / \mathrm{O}$ ratio } \\
\hline Mkt- $R_{f}$ & $\begin{array}{l}0.844^{* * *} \\
(37.49)\end{array}$ & $\begin{array}{l}1.103^{* * *} \\
(25.01)\end{array}$ & $\begin{array}{l}1.200^{* * *} \\
(23.53)\end{array}$ & $\begin{array}{l}0.881^{\text {*** }} \\
(27.20)\end{array}$ & $\begin{array}{l}1.093^{* * *} \\
(32.40)\end{array}$ & $\begin{array}{l}1.233^{* * * *} \\
(25.52)\end{array}$ & $\begin{array}{l}1.011^{* * *} \\
(26.00)\end{array}$ & $\begin{array}{l}1.094^{* * *} \\
(40.77)\end{array}$ & $\begin{array}{l}1.338^{* * *} \\
(25.12)\end{array}$ \\
\hline SMB & $\begin{array}{l}-0.212^{* * *} \\
(-6.35)\end{array}$ & $\begin{array}{l}-0.052 \\
(-0.63)\end{array}$ & $\begin{array}{l}0.337^{* *} \\
(2.36)\end{array}$ & $\begin{array}{l}-0.220^{* * *} \\
(-6.99)\end{array}$ & $\begin{array}{l}0.161^{* * *} \\
(3.28)\end{array}$ & $\begin{array}{l}0.521^{* * *} \\
(7.34)\end{array}$ & $\begin{array}{c}0.019 \\
(0.26)\end{array}$ & $\begin{array}{l}0.277^{* * *} \\
(4.66)\end{array}$ & $\begin{array}{l}0.491^{* * *} \\
(5.24)\end{array}$ \\
\hline HML & $\begin{array}{l}0.214^{* * *} \\
(4.75)\end{array}$ & $\begin{array}{l}0.248^{* * *} \\
(3.17)\end{array}$ & $\begin{array}{c}0.058 \\
(0.52)\end{array}$ & $\begin{array}{l}-0.132^{* * *} \\
(-3.24)\end{array}$ & $\begin{array}{l}-0.330^{* * *} \\
(-5.19)\end{array}$ & $\begin{array}{l}-0.746^{* * *} \\
(-9.77)\end{array}$ & $\begin{array}{l}-0.372^{* * *} \\
(-5.88)\end{array}$ & $\begin{array}{c}-0.073 \\
(-0.93)\end{array}$ & $\begin{array}{l}-0.559^{* * *} \\
(-5.53)\end{array}$ \\
\hline MOM & $\begin{array}{l}-0.003 \\
(-0.10)\end{array}$ & $\begin{array}{l}-0.011 \\
(-0.29)\end{array}$ & $\begin{array}{l}-0.092 \\
(-1.49)\end{array}$ & $\begin{array}{c}0.008 \\
(0.25)\end{array}$ & $\begin{array}{l}-0.116^{* * *} \\
(-2.65)\end{array}$ & $\begin{array}{l}-0.098^{* *} \\
(-2.00)\end{array}$ & $\begin{array}{l}-0.037 \\
(-0.80)\end{array}$ & $\begin{array}{l}-0.007 \\
(-0.18)\end{array}$ & $\begin{array}{l}-0.074 \\
(-1.42)\end{array}$ \\
\hline Constant & $\begin{array}{c}0.067 \\
(0.85)\end{array}$ & $\begin{array}{c}0.007 \\
(0.05)\end{array}$ & $\begin{array}{l}-0.010 \\
(-0.05)\end{array}$ & $\begin{array}{l}0.191^{* *} \\
(1.98)\end{array}$ & $\begin{array}{l}-0.003 \\
(-0.02)\end{array}$ & $\begin{array}{c}0.118 \\
(0.67)\end{array}$ & $\begin{array}{l}0.400^{* * *} \\
(3.04)\end{array}$ & $\begin{array}{c}0.042 \\
(0.33)\end{array}$ & $\begin{array}{l}-0.131 \\
(-0.74)\end{array}$ \\
\hline \multicolumn{10}{|c|}{ Panel C: Size } \\
\hline Mkt- $R_{f}$ & $\begin{array}{l}0.915^{* * *} \\
(37.78)\end{array}$ & $\begin{array}{l}1.019^{* * *} \\
(24.33)\end{array}$ & $\begin{array}{l}0.994^{* * *} \\
(21.27)\end{array}$ & $\begin{array}{l}0.957^{\text {*** }} \\
(41.72)\end{array}$ & $\begin{array}{l}1.081^{* * *} \\
(27.91)\end{array}$ & $\begin{array}{l}1.039^{* * *} \\
(22.06)\end{array}$ & $\begin{array}{l}1.107^{* * *} \\
(31.03)\end{array}$ & $\begin{array}{l}1.086^{* * *} \\
(38.41)\end{array}$ & $\begin{array}{l}1.022^{* * *} \\
(30.02)\end{array}$ \\
\hline SMB & $\begin{array}{l}-0.189^{* * *} \\
(-4.47)\end{array}$ & $\begin{array}{l}0.578^{* * * *} \\
(4.26)\end{array}$ & $\begin{array}{l}0.886^{* * *} \\
(6.82)\end{array}$ & $\begin{array}{l}-0.132^{* * *} \\
(-4.88)\end{array}$ & $\begin{array}{l}0.962^{* * *} \\
(11.97)\end{array}$ & $\begin{array}{l}1.413^{* * *} \\
(11.12)\end{array}$ & $\begin{array}{c}0.012 \\
(0.18)\end{array}$ & $\begin{array}{l}0.854^{* * * *} \\
(16.78)\end{array}$ & $\begin{array}{l}1.151^{* * *} \\
(21.44)\end{array}$ \\
\hline HML & $\begin{array}{l}0.201^{* * *} \\
(3.83)\end{array}$ & $\begin{array}{l}0.181^{* *} \\
(2.01)\end{array}$ & $\begin{array}{c}-0.006 \\
(-0.07)\end{array}$ & $\begin{array}{l}-0.265^{* * *} \\
(-8.76)\end{array}$ & $\begin{array}{l}-0.461^{* * *} \\
(-7.05)\end{array}$ & $\begin{array}{l}-0.475^{* * *} \\
(-7.39)\end{array}$ & $\begin{array}{l}-0.391^{* * *} \\
(-6.69)\end{array}$ & $\begin{array}{l}-0.319^{* * *} \\
(-5.66)\end{array}$ & $\begin{array}{l}-0.341^{* * *} \\
(-4.23)\end{array}$ \\
\hline MOM & $\begin{array}{c}0.006 \\
(0.21)\end{array}$ & $\begin{array}{c}0.005 \\
(0.11)\end{array}$ & $\begin{array}{r}0.021 \\
(0.37)\end{array}$ & $\begin{array}{l}-0.026 \\
(-0.92)\end{array}$ & $\begin{array}{c}0.015 \\
(0.31)\end{array}$ & $\begin{array}{c}0.022 \\
(0.43)\end{array}$ & $\begin{array}{l}-0.045 \\
(-1.09)\end{array}$ & $\begin{array}{l}-0.002 \\
(-0.05)\end{array}$ & $\begin{array}{c}0.020 \\
(0.36)\end{array}$ \\
\hline Constant & $\begin{array}{c}0.049 \\
(0.63)\end{array}$ & $\begin{array}{l}-0.115 \\
(-0.90)\end{array}$ & $\begin{array}{l}-0.106 \\
(-0.62)\end{array}$ & $\begin{array}{l}0.157^{*} \\
(1.91)\end{array}$ & $\begin{array}{c}0.108 \\
(0.80)\end{array}$ & $\begin{array}{l}-0.128 \\
(-0.78)\end{array}$ & $\begin{array}{l}0.242^{*} \\
(1.96)\end{array}$ & $\begin{array}{c}0.034 \\
(0.29)\end{array}$ & $\begin{array}{l}-0.191 \\
(-1.36)\end{array}$ \\
\hline
\end{tabular}

${ }^{t}$ statistics in parentheses based on Newey-West adjusted SEs.
${ }^{*} p<0.10,{ }^{* *} p<0.05,{ }^{* * *} p<0.01$ 
Table 12: The impact of financing constraints on the mean-reversion of firm profitability.

We regress the change of firm profitability on the lagged excess profitability relative to the aggregate profitability, and on the lagged change of profitability. We interact excess profitability with a lagged indicator of financing constraints (FC). LoFC ( $\mathrm{HiFC}$ ) is an indicator variable for the $30 \%$ observations that were the least (most) likely to be subject to financing constraints in the previous year. \%HiFC (\% LoFC) is the proportion of HiFC (LoFC) companies within the SIC3 industry. The estimation period is from 1977 to 2009 . We present average coefficient values and t-statistics from yearly crosssectional regressions.

\begin{tabular}{|c|c|c|c|c|c|c|}
\hline & $\begin{array}{c}(1) \\
\text { Baseline }\end{array}$ & $\begin{array}{l}(2) \\
\text { WW }\end{array}$ & $\begin{array}{l}(3) \\
\mathrm{P} / \mathrm{O}\end{array}$ & $\begin{array}{l}(4) \\
\text { Size }\end{array}$ & $\begin{array}{l}(5) \\
\text { LT rating }\end{array}$ & $\begin{array}{l}(6) \\
\text { ST rating }\end{array}$ \\
\hline $\mathrm{ROA}_{t-1}-\mathrm{ROA}_{t-1}^{\mathrm{agr}}$ & $\begin{array}{r}-0.269 \\
(-15.63)\end{array}$ & $\begin{array}{r}-0.346 \\
(-12.68)\end{array}$ & $\begin{array}{r}-0.457 \\
(-14.17)\end{array}$ & $\begin{array}{r}-0.372 \\
(-13.96)\end{array}$ & $\begin{array}{l}-0.234 \\
(-9.73)\end{array}$ & $\begin{array}{r}-0.270 \\
(-10.93)\end{array}$ \\
\hline $\mathrm{ROA}_{t-1}-\mathrm{ROA}_{t-2}$ & $\begin{array}{r}-0.173 \\
(-10.70)\end{array}$ & $\begin{array}{r}-0.163 \\
(-10.46)\end{array}$ & $\begin{array}{r}-0.157 \\
(-10.62)\end{array}$ & $\begin{array}{r}-0.166 \\
(-10.95)\end{array}$ & $\begin{array}{r}-0.205 \\
(-14.30)\end{array}$ & $\begin{array}{r}-0.207 \\
(-13.97)\end{array}$ \\
\hline$\left(\mathrm{ROA}_{t-1}-\mathrm{ROA}_{t-1}^{\mathrm{agr}}\right) \times \mathrm{HiFC}$ & & $\begin{array}{l}-0.062 \\
(-3.96)\end{array}$ & $\begin{array}{r}0.020 \\
(1.09)\end{array}$ & $\begin{array}{r}0.007 \\
(0.42)\end{array}$ & & \\
\hline$\left(\mathrm{ROA}_{t-1}-\mathrm{ROA}_{t-1}^{\mathrm{agr}}\right) \times \operatorname{LoFC}$ & & $\begin{array}{r}0.058 \\
(2.93)\end{array}$ & $\begin{array}{r}0.285 \\
(13.82)\end{array}$ & $\begin{array}{c}0.022 \\
(1.13)\end{array}$ & $\begin{array}{c}-0.059 \\
(-2.12)\end{array}$ & $\begin{array}{r}0.020 \\
(0.50)\end{array}$ \\
\hline$\left(\mathrm{ROA}_{t-1}-\mathrm{ROA}_{t-1}^{\mathrm{agr}}\right) \times \% \mathrm{HiFC}$ & & $\begin{array}{c}0.253 \\
(4.55)\end{array}$ & $\begin{array}{c}0.231 \\
(4.06)\end{array}$ & $\begin{array}{c}0.230 \\
(5.09)\end{array}$ & & \\
\hline$\left(\mathrm{ROA}_{t-1}-\mathrm{ROA}_{t-1}^{\mathrm{agr}}\right) \times \% \mathrm{LoFC}$ & & & & & $\begin{array}{l}-0.154 \\
(-2.18)\end{array}$ & $\begin{array}{r}0.167 \\
(1.13)\end{array}$ \\
\hline Constant & $\begin{array}{l}-0.016 \\
(-6.03)\end{array}$ & $\begin{array}{l}-0.017 \\
(-6.12)\end{array}$ & $\begin{array}{l}-0.017 \\
(-6.30)\end{array}$ & $\begin{array}{l}-0.016 \\
(-5.90)\end{array}$ & $\begin{array}{l}-0.019 \\
(-6.06)\end{array}$ & $\begin{array}{l}-0.019 \\
(-6.25)\end{array}$ \\
\hline $\begin{array}{l}\text { Observations } \\
R^{2}\end{array}$ & $\begin{array}{c}78445 \\
0.173\end{array}$ & $\begin{array}{c}72959 \\
0.181\end{array}$ & $\begin{array}{c}78445 \\
0.184\end{array}$ & $\begin{array}{c}78445 \\
0.180\end{array}$ & $\begin{array}{c}64375 \\
0.195\end{array}$ & $\begin{array}{c}64375 \\
0.193\end{array}$ \\
\hline
\end{tabular}


Table 13: The impact of financing constraints on the mean-reversion of firm profitability.

We regress the change of firm profitability on the lagged excess profitability relative to the SIC3 industry profitability, on the excess profitability of the industry relative to the aggregate profitability, and on the lagged change of profitability. We interact the excess profitability terms with a lagged indicator of financing constraints (FC). LoFC (HiFC) is an indicator variable for the $30 \%$ observations that were the least (most) likely to be subject to financing constraints in the previous year. \%HiFC (\% LoFC) is the proportion of HiFC ( $\mathrm{LoFC}$ ) companies within the SIC3 industry. The estimation period is from 1977 to 2009 . We present average coefficient values and t-statistics from yearly crosssectional regressions.

\begin{tabular}{|c|c|c|c|c|c|c|}
\hline & $\begin{array}{c}(1) \\
\text { Baseline }\end{array}$ & $\begin{array}{l}(2) \\
\text { WW }\end{array}$ & $\begin{array}{l}(3) \\
\mathrm{P} / \mathrm{O}\end{array}$ & $\begin{array}{l}(4) \\
\text { Size }\end{array}$ & $\begin{array}{l}(5) \\
\text { LT rating }\end{array}$ & $\begin{array}{l}(6) \\
\text { ST rating }\end{array}$ \\
\hline $\mathrm{ROA}_{t-1}-\mathrm{ROA}_{t-1}^{\mathrm{SIC} 3}$ & $\begin{array}{r}-0.272 \\
(-16.11)\end{array}$ & $\begin{array}{r}-0.352 \\
(-12.88)\end{array}$ & $\begin{array}{c}-0.484 \\
(-14.07)\end{array}$ & $\begin{array}{r}-0.382 \\
(-13.55)\end{array}$ & $\begin{array}{r}-0.236 \\
(-10.21)\end{array}$ & $\begin{array}{r}-0.274 \\
(-11.38)\end{array}$ \\
\hline $\mathrm{ROA}_{t-1}^{\mathrm{SIC} 3}-\mathrm{ROA}_{t-1}^{\mathrm{agr}}$ & $\begin{array}{l}-0.238 \\
(-7.81)\end{array}$ & $\begin{array}{l}-0.305 \\
(-7.66)\end{array}$ & $\begin{array}{l}-0.303 \\
(-8.89)\end{array}$ & $\begin{array}{l}-0.283 \\
(-8.73)\end{array}$ & $\begin{array}{l}-0.208 \\
(-4.20)\end{array}$ & $\begin{array}{l}-0.244 \\
(-6.14)\end{array}$ \\
\hline $\mathrm{ROA}_{t-1}-\mathrm{ROA}_{t-2}$ & $\begin{array}{r}-0.173 \\
(-10.72)\end{array}$ & $\begin{array}{r}-0.163 \\
(-10.45)\end{array}$ & $\begin{array}{r}-0.157 \\
(-10.62)\end{array}$ & $\begin{array}{r}-0.165 \\
(-10.88)\end{array}$ & $\begin{array}{r}-0.205 \\
(-13.99)\end{array}$ & $\begin{array}{r}-0.207 \\
(-13.88)\end{array}$ \\
\hline$\left(\mathrm{ROA}_{t-1}-\mathrm{ROA}_{t-1}^{\mathrm{SIC} 3}\right) \times \mathrm{HiFC}$ & & $\begin{array}{l}-0.057 \\
(-3.78)\end{array}$ & $\begin{array}{r}0.028 \\
(1.53)\end{array}$ & $\begin{array}{c}0.009 \\
(0.62)\end{array}$ & & \\
\hline$\left(\mathrm{ROA}_{t-1}-\mathrm{ROA}_{t-1}^{\mathrm{SIC} 3}\right) \times \mathrm{LoFC}$ & & $\begin{array}{c}0.032 \\
(1.75)\end{array}$ & $\begin{array}{r}0.277 \\
(13.02)\end{array}$ & $\begin{array}{l}-0.009 \\
(-0.49)\end{array}$ & $\begin{array}{l}-0.095 \\
(-3.54)\end{array}$ & $\begin{array}{l}-0.070 \\
(-1.76)\end{array}$ \\
\hline$\left(\mathrm{ROA}_{t-1}-\mathrm{ROA}_{t-1}^{\mathrm{SIC} 3}\right) \times \% \mathrm{HiFC}$ & & $\begin{array}{c}0.255 \\
(4.59)\end{array}$ & $\begin{array}{c}0.265 \\
(4.33)\end{array}$ & $\begin{array}{c}0.243 \\
(4.86)\end{array}$ & & \\
\hline$\left(\mathrm{ROA}_{t-1}-\mathrm{ROA}_{t-1}^{\mathrm{SIC} 3}\right) \times \% \mathrm{LoFC}$ & & & & & $\begin{array}{l}-0.164 \\
(-2.25)\end{array}$ & $\begin{array}{c}0.186 \\
(1.23)\end{array}$ \\
\hline$\left(\mathrm{ROA}_{t-1}^{\mathrm{SIC} 3}-\mathrm{ROA}_{t-1}^{\mathrm{agr}}\right) \times \mathrm{HiFC}$ & & $\begin{array}{c}-0.193 \\
(-4.32)\end{array}$ & $\begin{array}{l}-0.098 \\
(-2.51)\end{array}$ & $\begin{array}{l}-0.081 \\
(-1.71)\end{array}$ & & \\
\hline$\left(\mathrm{ROA}_{t-1}^{\mathrm{SIC} 3}-\mathrm{ROA}_{t-1}^{\mathrm{agr}}\right) \times \mathrm{LoFC}$ & & $\begin{array}{c}0.121 \\
(3.57)\end{array}$ & $\begin{array}{c}0.274 \\
(8.53)\end{array}$ & $\begin{array}{c}0.086 \\
(2.81)\end{array}$ & $\begin{array}{r}0.052 \\
(1.49)\end{array}$ & $\begin{array}{c}0.188 \\
(4.65)\end{array}$ \\
\hline$\left(\mathrm{ROA}_{t-1}^{\mathrm{SIC} 3}-\mathrm{ROA}_{t-1}^{\mathrm{agr}}\right) \times \% \mathrm{HiFC}$ & & $\begin{array}{c}0.273 \\
(2.47)\end{array}$ & $\begin{array}{r}0.071 \\
(1.14)\end{array}$ & $\begin{array}{r}0.116 \\
(1.28)\end{array}$ & & \\
\hline$\left(\mathrm{ROA}_{t-1}^{\mathrm{SIC} 3}-\mathrm{ROA}_{t-1}^{\mathrm{agr}}\right) \times \% \mathrm{LoFC}$ & & & & & $\begin{array}{l}-0.161 \\
(-1.46)\end{array}$ & $\begin{array}{r}0.047 \\
(0.38)\end{array}$ \\
\hline Constant & $\begin{array}{l}-0.016 \\
(-6.05)\end{array}$ & $\begin{array}{l}-0.017 \\
(-6.31)\end{array}$ & $\begin{array}{l}-0.017 \\
(-6.47)\end{array}$ & $\begin{array}{l}-0.016 \\
(-6.08)\end{array}$ & $\begin{array}{l}-0.019 \\
(-6.26)\end{array}$ & $\begin{array}{l}-0.019 \\
(-6.16)\end{array}$ \\
\hline $\begin{array}{l}\text { Observations } \\
R^{2}\end{array}$ & $\begin{array}{c}78445 \\
0.175\end{array}$ & $\begin{array}{c}72959 \\
0.186\end{array}$ & $\begin{array}{c}78445 \\
0.189\end{array}$ & $\begin{array}{c}78445 \\
0.185\end{array}$ & $\begin{array}{c}64375 \\
0.198\end{array}$ & $\begin{array}{c}64375 \\
0.196\end{array}$ \\
\hline
\end{tabular}


Table 14: Time-series regressions of double-sorted portfolio returns by abnormal firm profitability and industry percentage of financially constrained firms.

We regress value-weighted monthly excess returns of portfolios on three Fama-French factors and the momentum factor. We merge Compustat fundamentals data with CRSP returns and use all firms that satisfy our fundamentals data requirements and have returns data. We construct independently double-sorted portfolios at the end of June of year t, based on year t-1 sector measures of financing constraints and firm abnormal profitability. Low \% of constrained firms (High) are the bottom (top) three deciles of observations based on the SIC3 percentage of financially constrained firms. Low rel. ROA (High rel. ROA) are the bottom (top) three deciles of observations based on previous year's difference between firm profitability and its SIC3 industry profitability. Panel A uses the WW index, Panel B uses the P/O ratio, and Panel C the size (total assets) as proxy of FC. See table 11 for details on explanatory variables. Regressions are estimated on the period July 1977 to December 2009, i.e. 390 monthly observations. We present t-statistics using Newey-West standard errors with 4 lags.

\begin{tabular}{|c|c|c|c|c|c|c|c|c|c|}
\hline & \multicolumn{3}{|c|}{ Low $\%$ of constrained firms } & \multicolumn{3}{|c|}{ Medium $\%$ of constrained firms } & \multicolumn{3}{|c|}{ High $\%$ of constrained firms } \\
\hline & Low rel. ROA & Med rel. ROA & High rel. ROA & Low rel. ROA & Med rel. ROA & High rel. ROA & Low rel. ROA & Med rel. ROA & High rel. ROA \\
\hline & \multicolumn{9}{|c|}{ Panel A: WW index } \\
\hline Mkt- $\mathrm{R}_{\mathrm{f}}$ & $\begin{array}{l}1.130^{* * *} \\
(16.96)\end{array}$ & $\begin{array}{l}0.973^{* * *} \\
(43.63)\end{array}$ & $\begin{array}{l}0.917^{* * *} \\
(26.66)\end{array}$ & $\begin{array}{l}1.177^{* * *} \\
(27.38)\end{array}$ & $\begin{array}{l}0.986^{* * *} \\
(47.33)\end{array}$ & $\begin{array}{l}0.993^{* * *} \\
(36.93)\end{array}$ & $\begin{array}{l}1.041^{* * * *} \\
(20.40)\end{array}$ & $\begin{array}{l}0.946^{* * *} \\
(34.78)\end{array}$ & $\begin{array}{l}0.985^{* * *} \\
(27.16)\end{array}$ \\
\hline SMB & $\begin{array}{l}0.160^{* *} \\
(2.36)\end{array}$ & $\begin{array}{l}-0.179^{* * *} \\
(-4.64)\end{array}$ & $\begin{array}{l}-0.249^{* * *} \\
(-4.45)\end{array}$ & $\begin{array}{l}0.647^{* * *} \\
(8.85)\end{array}$ & $\begin{array}{c}0.061 \\
(1.40)\end{array}$ & $\begin{array}{l}0.101^{* *} \\
(2.33)\end{array}$ & $\begin{array}{l}0.430^{* * *} \\
(4.06)\end{array}$ & $\begin{array}{l}-0.089^{*} \\
(-1.68)\end{array}$ & $\begin{array}{l}-0.147^{* *} \\
(-2.46)\end{array}$ \\
\hline HML & $\begin{array}{c}0.028 \\
(0.24)\end{array}$ & $\begin{array}{l}0.272^{* * *} \\
(7.09)\end{array}$ & $\begin{array}{c}0.052 \\
(0.85)\end{array}$ & $\begin{array}{l}-0.288^{* *} \\
(-2.55)\end{array}$ & $\begin{array}{l}-0.077^{*} \\
(-1.66)\end{array}$ & $\begin{array}{l}-0.352^{* * *} \\
(-7.82)\end{array}$ & $\begin{array}{l}-0.550^{* * *} \\
(-6.46)\end{array}$ & $\begin{array}{l}-0.250^{* * *} \\
(-5.16)\end{array}$ & $\begin{array}{l}-0.467^{* * *} \\
(-8.19)\end{array}$ \\
\hline MOM & $\begin{array}{l}-0.184^{* *} \\
(-2.52)\end{array}$ & $\begin{array}{c}0.015 \\
(0.66)\end{array}$ & $\begin{array}{c}0.042 \\
(1.08)\end{array}$ & $\begin{array}{l}-0.212^{* * *} \\
(-3.22)\end{array}$ & $\begin{array}{l}-0.047 \\
(-1.28)\end{array}$ & $\begin{array}{l}-0.147^{* * *} \\
(-3.64)\end{array}$ & $\begin{array}{l}-0.001 \\
(-0.02)\end{array}$ & $\begin{array}{l}-0.073 \\
(-1.50)\end{array}$ & $\begin{array}{l}0.077^{* *} \\
(2.13)\end{array}$ \\
\hline Constant & $\begin{array}{r}-0.047 \\
(-0.23) \\
\end{array}$ & $\begin{array}{r}-0.022 \\
(-0.32) \\
\end{array}$ & $\begin{array}{r}0.003 \\
(0.03) \\
\end{array}$ & $\begin{array}{r}-0.033 \\
(-0.20) \\
\end{array}$ & $\begin{array}{r}0.041 \\
(0.43) \\
\end{array}$ & $\begin{array}{l}0.246^{* *} \\
(2.21) \\
\end{array}$ & $\begin{array}{r}0.246 \\
(1.38) \\
\end{array}$ & $\begin{array}{l}0.252^{*} \\
(1.93) \\
\end{array}$ & $\begin{array}{l}0.285^{* *} \\
(2.25) \\
\end{array}$ \\
\hline & \multicolumn{9}{|c|}{ Panel B: $\mathrm{P} / \mathrm{O}$ ratio } \\
\hline Mkt- $\mathrm{R}_{\mathrm{f}}$ & $\begin{array}{l}1.030^{* * *} \\
(21.65)\end{array}$ & $\begin{array}{l}0.922^{* * *} \\
(28.90)\end{array}$ & $\begin{array}{l}0.852^{* * *} \\
(23.15)\end{array}$ & $\begin{array}{l}1.225^{* * *} \\
(25.83)\end{array}$ & $\begin{array}{l}1.024^{* * *} \\
(41.41)\end{array}$ & $\begin{array}{l}1.024^{* * *} \\
(38.70)\end{array}$ & $\begin{array}{l}1.025^{* * *} \\
(20.30)\end{array}$ & $\begin{array}{l}0.947^{* * *} \\
(26.59)\end{array}$ & $\begin{array}{l}1.005^{* * *} \\
(26.53)\end{array}$ \\
\hline SMB & $\begin{array}{c}0.111 \\
(1.37)\end{array}$ & $\begin{array}{l}-0.101^{* * *} \\
(-3.01)\end{array}$ & $\begin{array}{l}-0.157^{* * *} \\
(-2.76)\end{array}$ & $\begin{array}{l}0.512^{* * *} \\
(5.95)\end{array}$ & $\begin{array}{l}-0.052 \\
(-1.42)\end{array}$ & $\begin{array}{l}-0.053 \\
(-1.19)\end{array}$ & $\begin{array}{l}0.574^{* * *} \\
(5.19)\end{array}$ & $\begin{array}{l}-0.085 \\
(-1.15)\end{array}$ & $\begin{array}{l}-0.115^{*} \\
(-1.76)\end{array}$ \\
\hline HML & $\begin{array}{l}0.401^{* * * *} \\
(5.25)\end{array}$ & $\begin{array}{l}0.280^{* * *} \\
(4.78)\end{array}$ & $\begin{array}{l}0.123^{*} \\
(1.74)\end{array}$ & $\begin{array}{l}-0.355^{* * *} \\
(-3.78)\end{array}$ & $\begin{array}{c}0.074 \\
(1.59)\end{array}$ & $\begin{array}{l}-0.375^{* * *} \\
(-7.74)\end{array}$ & $\begin{array}{l}-0.675^{* * *} \\
(-10.57)\end{array}$ & $\begin{array}{l}-0.343^{* * *} \\
(-4.59)\end{array}$ & $\begin{array}{l}-0.450^{* * *} \\
(-7.01)\end{array}$ \\
\hline MOM & $\begin{array}{l}-0.069^{* *} \\
(-2.31)\end{array}$ & $\begin{array}{c}0.005 \\
(0.14)\end{array}$ & $\begin{array}{r}0.028 \\
(0.63)\end{array}$ & $\begin{array}{l}-0.228^{* * *} \\
(-2.97)\end{array}$ & $\begin{array}{l}-0.025 \\
(-0.80)\end{array}$ & $\begin{array}{l}-0.032 \\
(-1.11)\end{array}$ & $\begin{array}{l}-0.039 \\
(-0.88)\end{array}$ & $\begin{array}{l}-0.107^{*} \\
(-1.67)\end{array}$ & $\begin{array}{c}0.023 \\
(0.58)\end{array}$ \\
\hline Constant & $\begin{array}{r}0.055 \\
(0.37) \\
\end{array}$ & $\begin{array}{c}0.099 \\
(1.00) \\
\end{array}$ & $\begin{array}{r}0.082 \\
(0.72) \\
\end{array}$ & $\begin{array}{r}0.072 \\
(0.36) \\
\end{array}$ & $\begin{array}{r}0.039 \\
(0.47) \\
\end{array}$ & $\begin{array}{l}0.224^{* *} \\
(2.39) \\
\end{array}$ & $\begin{array}{c}0.162 \\
(1.01) \\
\end{array}$ & $\begin{array}{c}0.046 \\
(0.29) \\
\end{array}$ & $\begin{array}{r}0.196 \\
(1.45) \\
\end{array}$ \\
\hline Mkt- $\mathrm{R}_{\mathrm{f}}$ & $\begin{array}{l}1.124^{* * *} \\
(17.46)\end{array}$ & $\begin{array}{c}0.977^{* * *} \\
(45.84)\end{array}$ & $\begin{array}{l}0.925^{* * *} \\
(26.47)\end{array}$ & $\begin{array}{l}1.202^{* * *} \\
(26.54)\end{array}$ & $\begin{array}{c}\text { Panel C: Size } \\
0.999^{* * * *} \\
(43.76)\end{array}$ & $\begin{array}{l}0.993^{* * *} \\
(37.18)\end{array}$ & $\begin{array}{l}1.017^{* * *} \\
(19.94)\end{array}$ & $\begin{array}{l}0.888^{* * *} \\
(31.05)\end{array}$ & $\begin{array}{l}0.928^{* * * *} \\
(23.62)\end{array}$ \\
\hline SMB & $\begin{array}{l}0.215^{* * *} \\
(2.69)\end{array}$ & $\begin{array}{l}-0.165^{* * *} \\
(-4.55)\end{array}$ & $\begin{array}{l}-0.207^{* * *} \\
(-3.45)\end{array}$ & $\begin{array}{l}0.621^{* * *} \\
(7.04)\end{array}$ & $\begin{array}{c}0.053 \\
(1.17)\end{array}$ & $\begin{array}{c}0.017 \\
(0.36)\end{array}$ & $\begin{array}{l}0.442^{* * *} \\
(4.28)\end{array}$ & $\begin{array}{l}-0.104^{* *} \\
(-2.01)\end{array}$ & $\begin{array}{l}-0.098 \\
(-1.49)\end{array}$ \\
\hline HML & $\begin{array}{c}0.021 \\
(0.16)\end{array}$ & $\begin{array}{l}0.247^{* * *} \\
(6.23)\end{array}$ & $\begin{array}{r}0.047 \\
(0.75)\end{array}$ & $\begin{array}{l}-0.375^{* * *} \\
(-3.37)\end{array}$ & $\begin{array}{l}-0.076 \\
(-1.48)\end{array}$ & $\begin{array}{l}-0.393^{* * *} \\
(-6.65)\end{array}$ & $\begin{array}{l}-0.492^{* * *} \\
(-4.35)\end{array}$ & $\begin{array}{l}-0.122^{*} \\
(-1.86)\end{array}$ & $\begin{array}{l}-0.363^{* * *} \\
(-3.46)\end{array}$ \\
\hline MOM & $\begin{array}{l}-0.198^{* *} \\
(-2.26)\end{array}$ & $\begin{array}{c}0.016 \\
(0.70)\end{array}$ & $\begin{array}{c}0.051 \\
(1.23)\end{array}$ & $\begin{array}{l}-0.258^{* * *} \\
(-3.92)\end{array}$ & $\begin{array}{l}-0.085^{* * *} \\
(-2.94)\end{array}$ & $\begin{array}{l}-0.164^{* * *} \\
(-3.80)\end{array}$ & $\begin{array}{c}0.060 \\
(0.81)\end{array}$ & $\begin{array}{c}0.017 \\
(0.38)\end{array}$ & $\begin{array}{l}0.181^{* * *} \\
(3.38)\end{array}$ \\
\hline Constant & $\begin{array}{c}0.021 \\
(0.11)\end{array}$ & $\begin{array}{c}0.002 \\
(0.03)\end{array}$ & $\begin{array}{l}0.101 \\
(0.92)\end{array}$ & $\begin{array}{l}-0.039 \\
(-0.22)\end{array}$ & $\begin{array}{l}-0.004 \\
(-0.04)\end{array}$ & $\begin{array}{c}0.166 \\
(1.51)\end{array}$ & $\begin{array}{c}0.158 \\
(0.84)\end{array}$ & $\begin{array}{l}0.231^{*} \\
(1.80)\end{array}$ & $\begin{array}{l}0.244^{*} \\
(1.79)\end{array}$ \\
\hline
\end{tabular}

$t$ statistics in parentheses based on
$p<0.10,{ }^{* *} p<0.05,{ }^{* * *} p<0.01$ 
Figure 1: Business cycle variables, annual data.

Presented are the annual real U.S. GDP growth, the average spread between the 3-month Commercial paper and the corresponding T-Bill (CP spread), the average spread between seasoned Aaa and Baa bonds by Moody's (Bond spread), and the average spread between the 10-year T-note rate and the 3-month T-Bill rate (Term spread). Source: Federal Reserve, author's calculations.

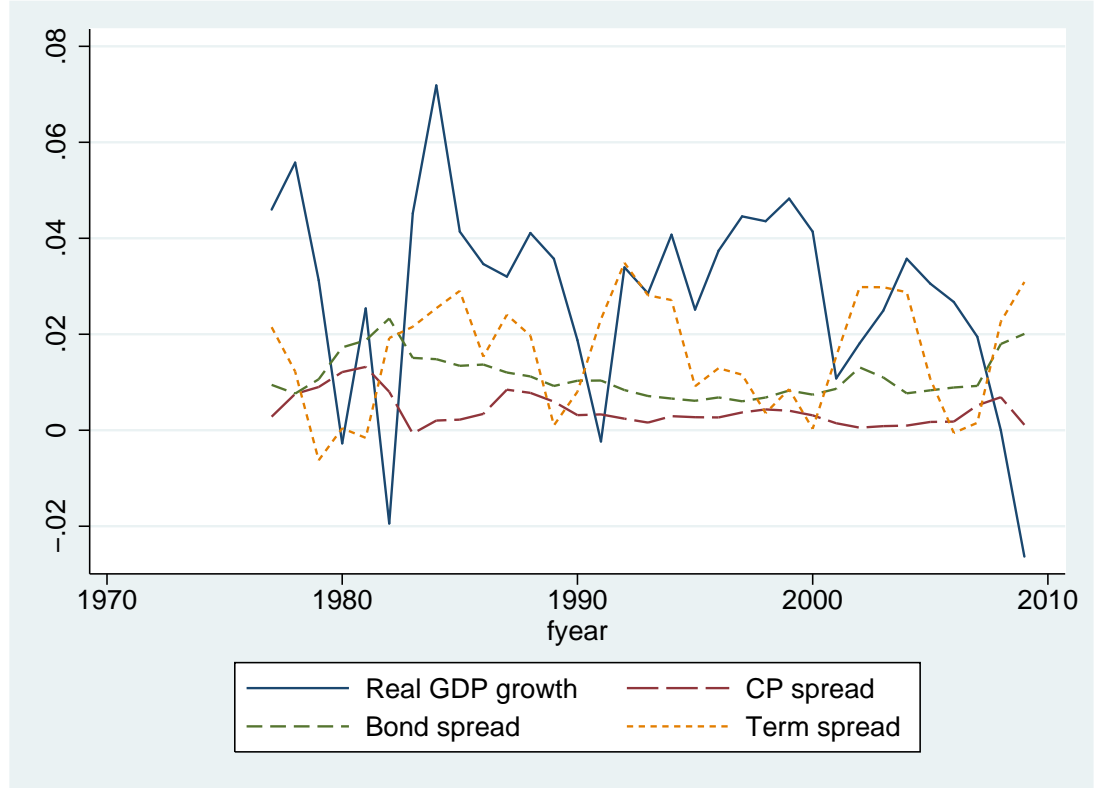


Figure 2: Business cycle variables adjustment.

We plot three macro variables before and after orthogonalization. Presented are the change in the average CP spread, the change in the average Bond spread, and the change in the average Term spread. All variables are standardized. See text for details on the adjustment procedure. Source: Federal Reserve, author's calculations.
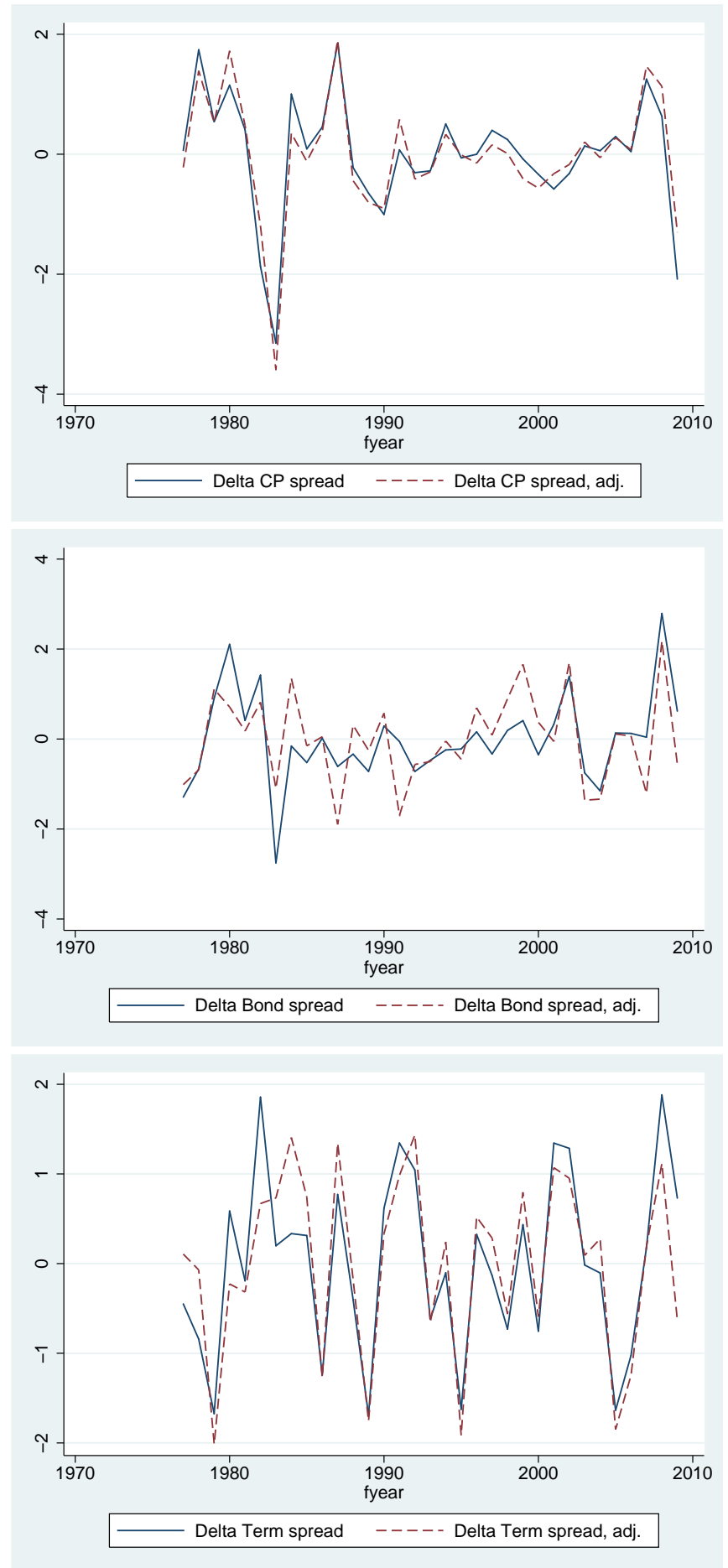
Figure 3: Herfindahl-Hirschman index and the industry dispersion of firm Lerner indexes.

We plot the Hoberg-Phillips (2010) fitted HHI data on the horizontal axis and the standard deviation of firm Lerner indexes within the SIC3 industry on the vertical axis. We present plots for three years within our sample period: 1980, 1995 and 2005.

1980, equally-weighted

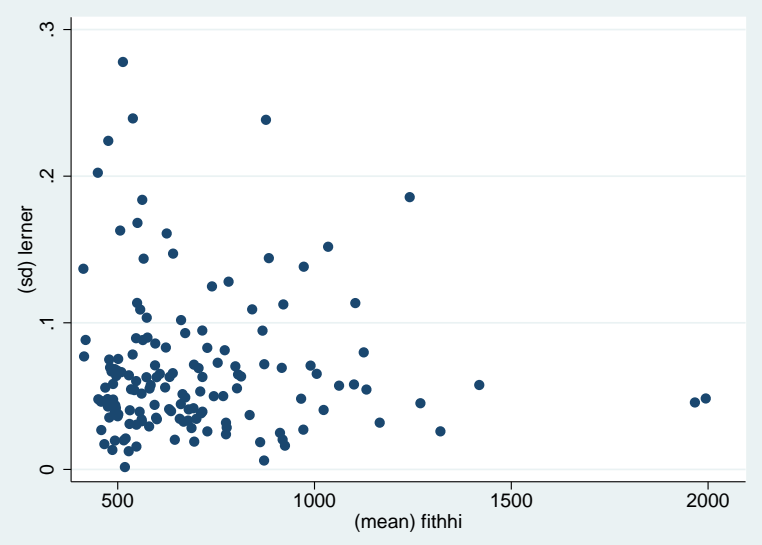

1995, equally-weighted

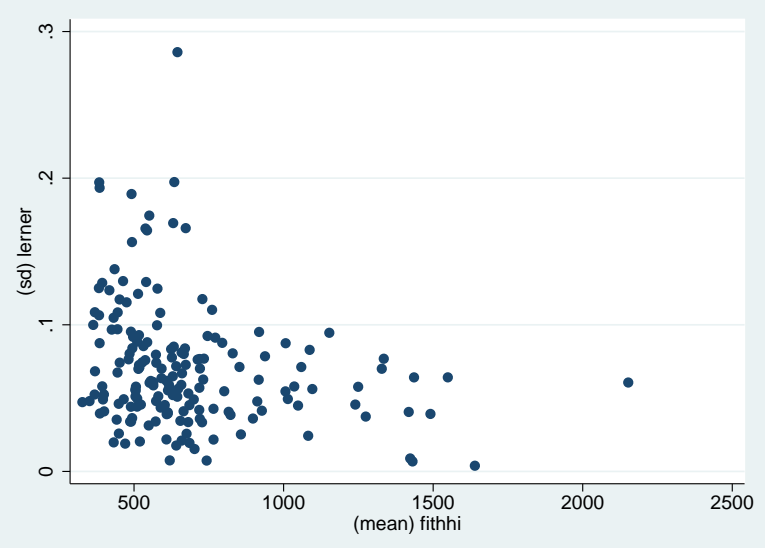

2005, equally-weighted

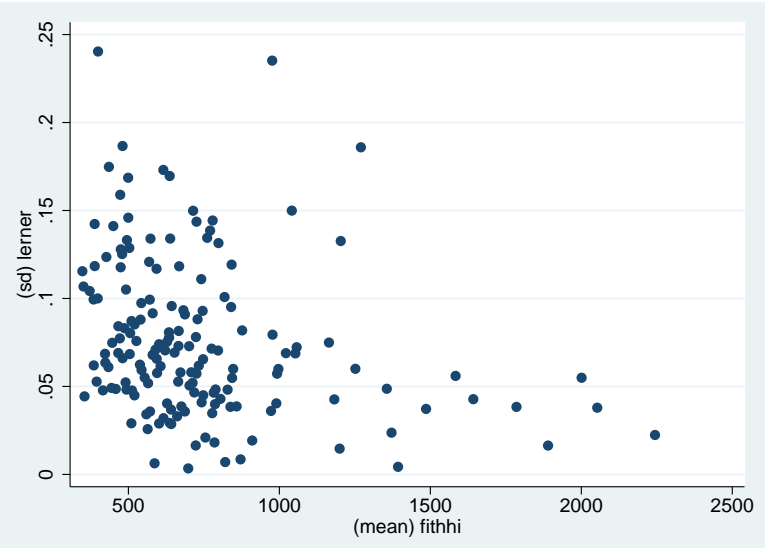

1980, sales-weighted

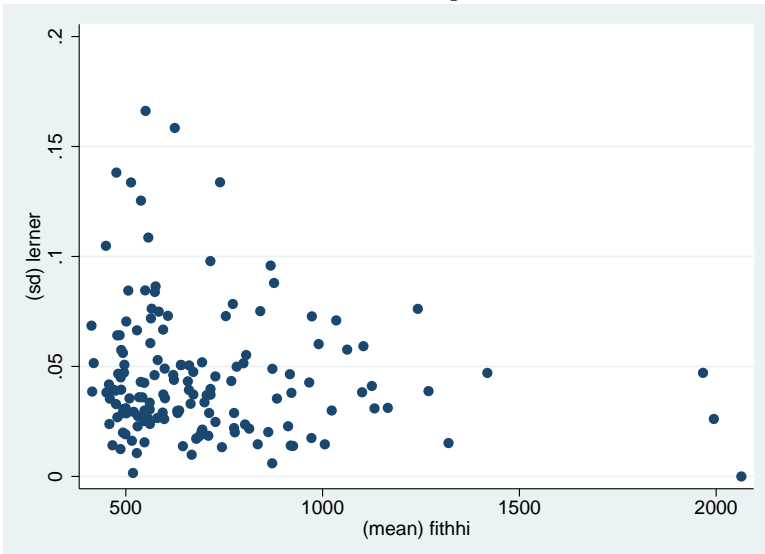

1995, sales-weighted

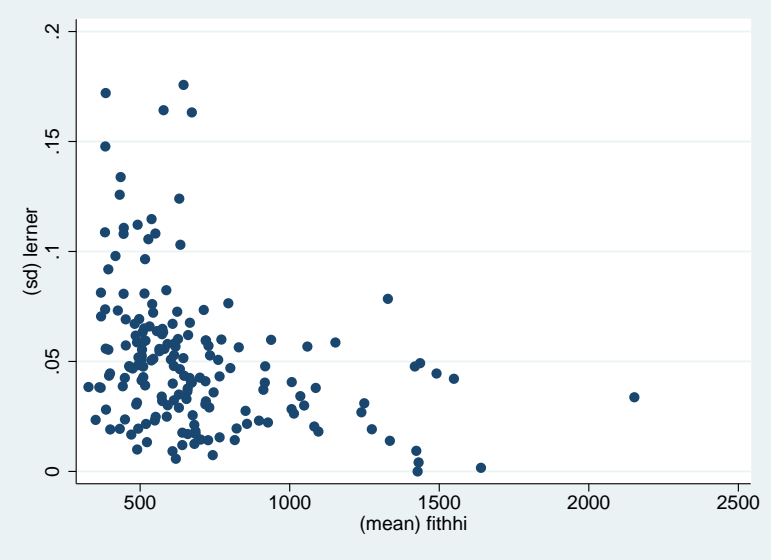

2005, sales-weighted

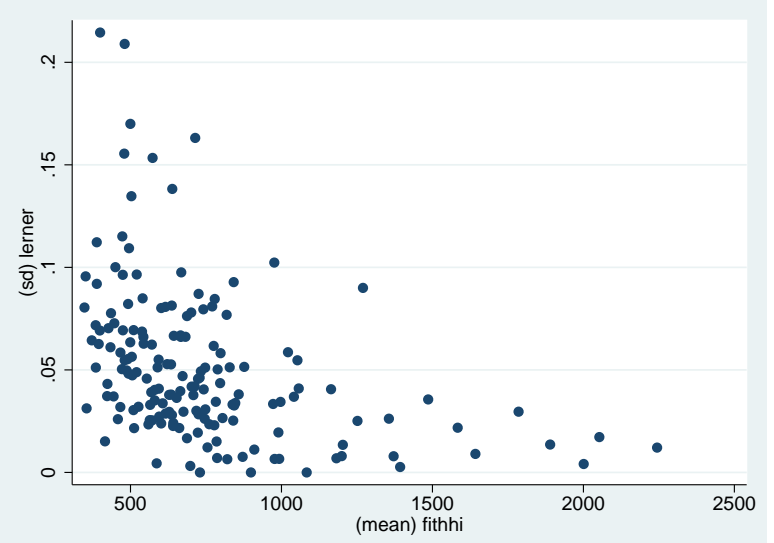


Figure 4: Abnormal returns from moving-window regressions of portfolio returns in a four-factor framework.

We regress value-weighted monthly excess returns of double-sorted portfolios on three Fama-French factors and the momentum factor with a 4-year moving window. See table 11 for details on portfolio sorting. We present results for the four corner portfolios corresponding to High/Low product market competition and High/Low financing constraints. SEs used for t-stats are N-W adjusted (4 lags). Shaded areas are NBER recession months.

Alpha

Panel A: WW index

t-stat of Alpha

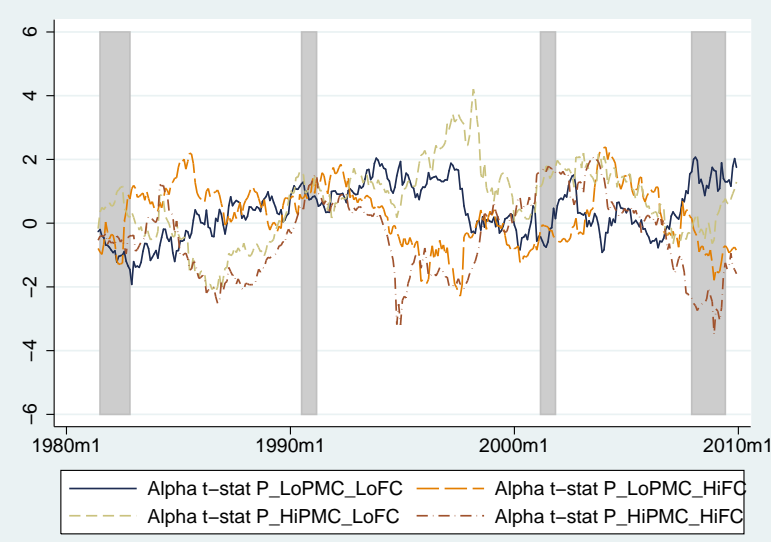

Panel B: $\mathrm{P} / \mathrm{O}$ ratio
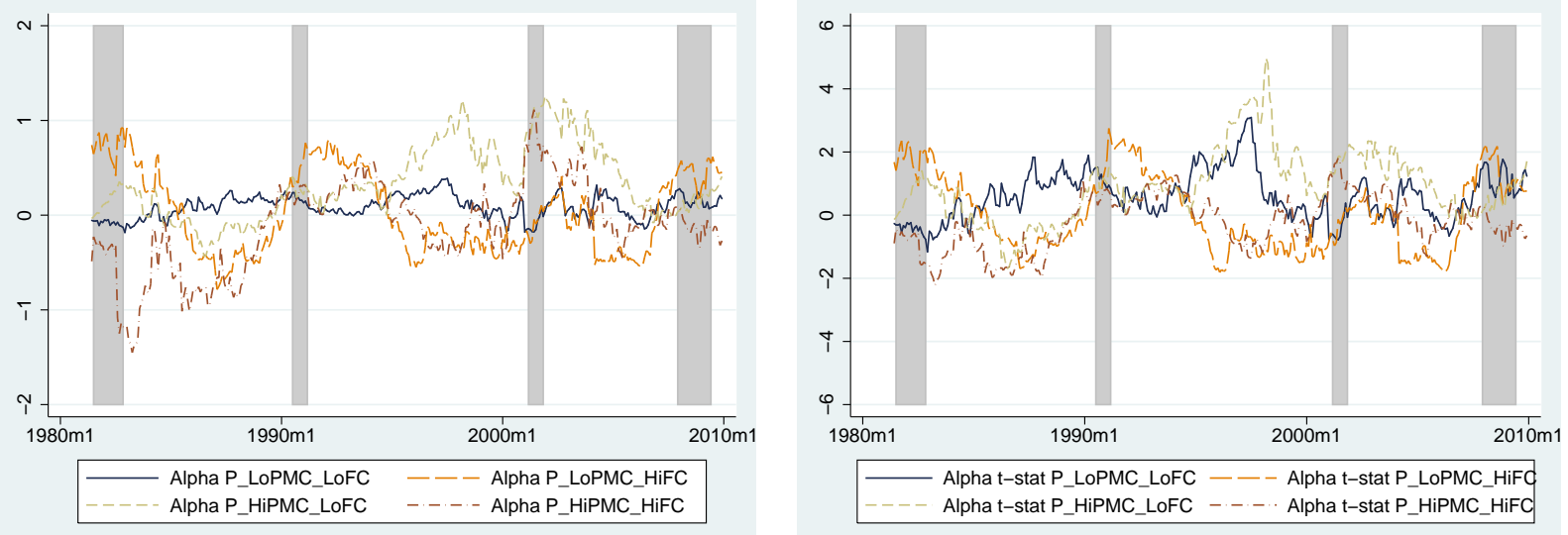

Panel C: Size
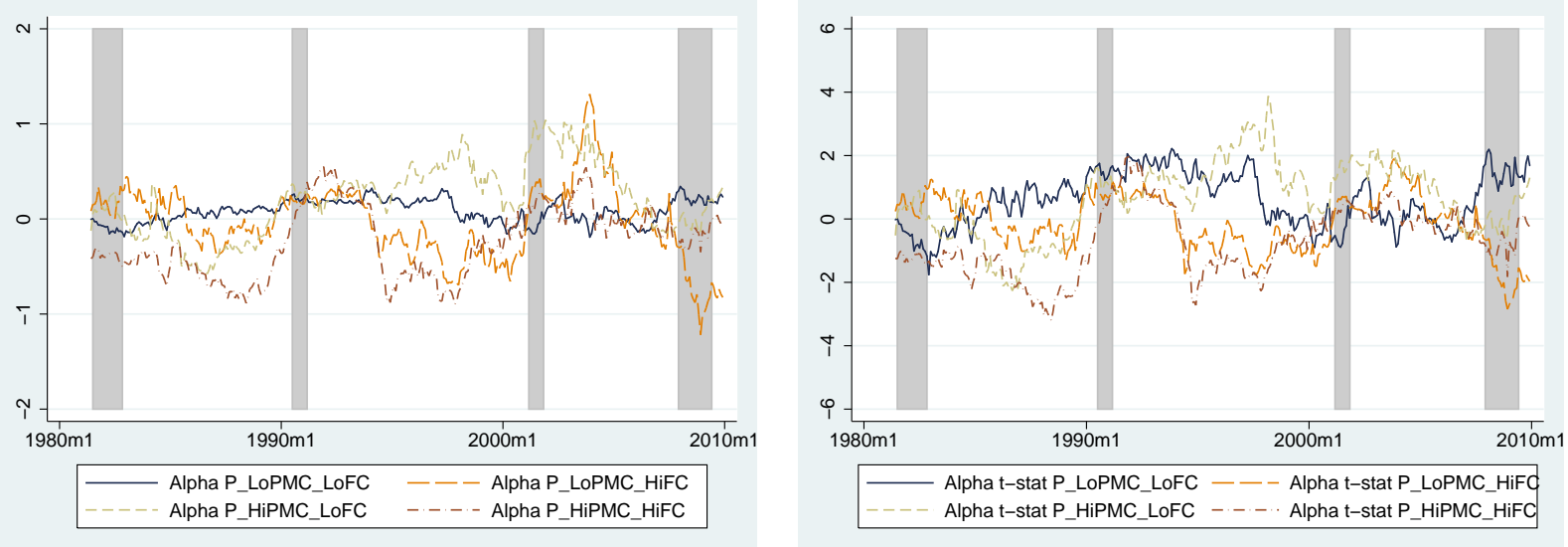